RD10-158

March 30, 2013

PRATT \& WHITNEY ROCKETDYNE, A UNITED TECHONOLOGY COMPANY

\title{
Concentrating Solar Power - Central Receiver Panel Component Fabrication and Testing FINAL REPORT
}

Project Period - September 25, 2008 thru December 30, 2012

PROGRAM Michael McDowell, RLA-21

MANAGER: 6633 Canoga Avenue Canoga Park, CA 91309

TELEPHONE: (818) 586-5256

FAX: (818) $586-1330$

E-MAIL: michael.mcdowell@pwr.utc.com
TEAM LEAD: Kris Miner, RLA-21 6633 Canoga Avenue Canoga Park, CA 91309

TELEPHONE: (818) 586-7854

FAX: (818) 586-1330

E-MAIL: kristan.miner@pwr.utc.com

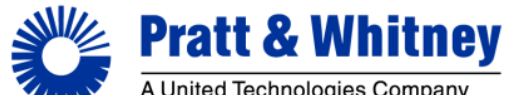

Pratt \& Whitney Rocketdyne, Inc. 6633 Canoga Avenue

P.O. Box 7922

Canoga Park, CA $91309-7922$ 


\section{Executive Summary}

The objective of this project is to complete a design of an advanced concentrated solar panel and demonstrate the manufacturability of key components. Then confirm the operation of the key components under prototypic solar flux conditions. This work is an important step in reducing the levelized cost of energy (LCOE) from a central receiver solar power plant. The key technical risk to building larger power towers is building the larger receiver systems. Therefore, this proposed technology project includes the design of an advanced molten salt prototypic sub-scale receiver panel that can be utilized into a large receiver system. Then complete the fabrication and testing of key components of the receive design that will be used to validate the design.

This project shall have a significant impact on solar thermal power plant design. Receiver panels of suitable size for utility scale plants are a key element to a solar power tower plant. Many subtle and complex manufacturing processes are involved in producing a reliable, robust receiver panel. Given the substantial size difference between receiver panels manufactured in the past and those needed for large plant designs, the manufacture and demonstration on prototype receiver panel components with representative features of a full-sized panel will be important to improving the build process for commercial success. Given the thermal flux limitations of the test facility, the panel components cannot be rendered full size.

Significance changes occurred in the projects technical strategies from project initiation to the accomplishments described herein. The initial strategy was to define cost improvements for the receiver, design and build a scale prototype receiver and test, on sun, with a molten salt heat transport system. DOE had committed to constructing a molten salt heat transport loop to support receiver testing at the top of the NSTTF tower. Because of funding constraints this did not happen. A subsequent plan to test scale prototype receiver, off sun but at temperature, at a molten salt loop at ground level adjacent to the tower also had to be abandoned. Thus, no test facility existed for a molten salt receiver test. As a result, PWR completed the prototype receiver design and then fabricated key components for testing instead of fabricating the complete prototype receiver.

A number of innovative design ideas have been developed. Key features of the receiver panel have been identified. This evaluation includes input from Solar 2, personal experience of people working on these programs and meetings with Sandia.

Key components of the receiver design and key processes used to fabricate a receiver have been selected for further evaluation. The Test Plan, Concentrated Solar Power Receiver In Cooperation with the Department of Energy and Sandia National Laboratory was written to define the scope of the testing to be completed as well as to provide details related to the hardware, instrumentation, and data acquisition. The document contains a list of test objectives, a test matrix, and an associated test box showing the operating points to be tested.

Test Objectives:

1. Demonstrate low-cost manufacturability

2. Demonstrate robustness of two different tube base materials

3. Collect temperature data during on sun operation

4. Demonstrate long term repeated daily operation of heat shields

5. $\quad$ Complete pinhole tube weld repairs

6. Anchor thermal models

This report discusses the tests performed, the results, and implications for design improvements and LCOE reduction. 


\section{CONTENTS}

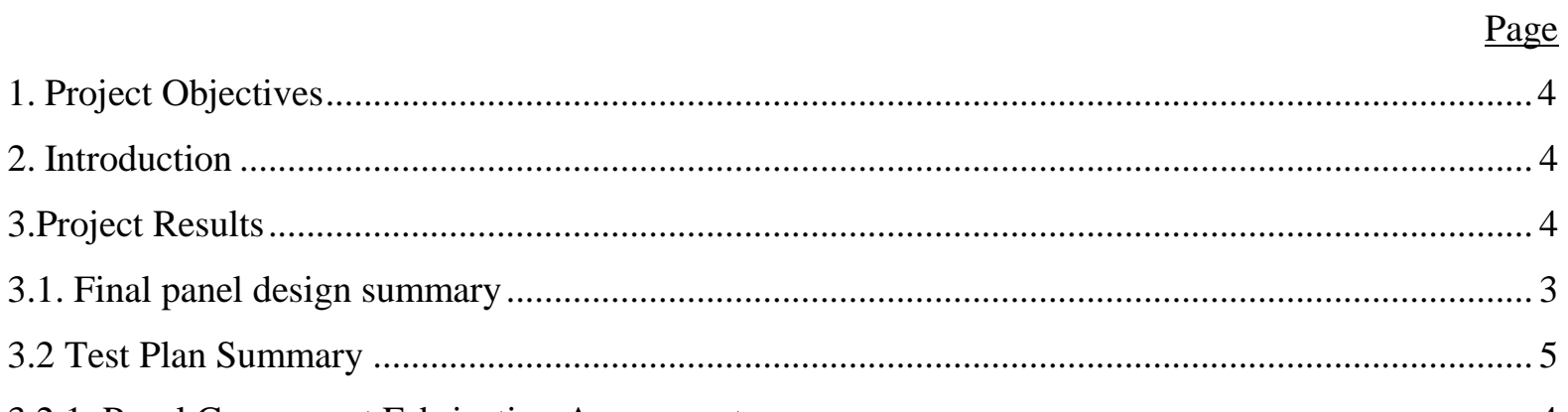

3.2.1 Panel Component Fabrication Assessment ............................................................................ 4

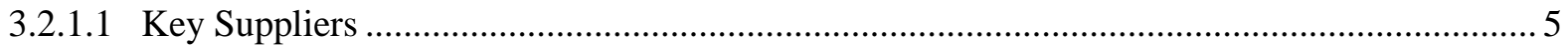

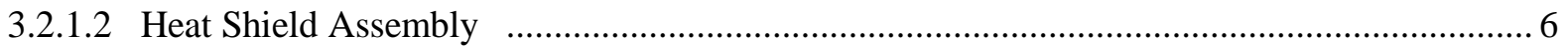

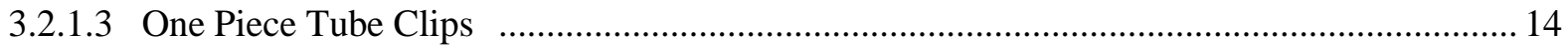

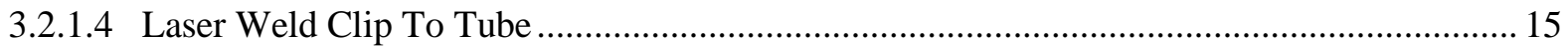

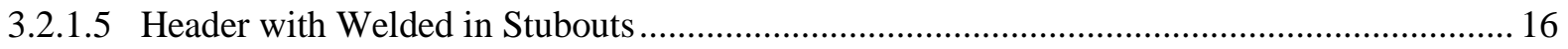

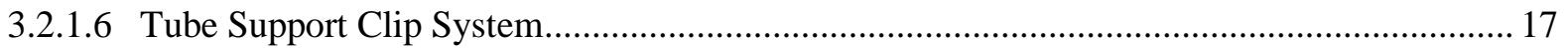

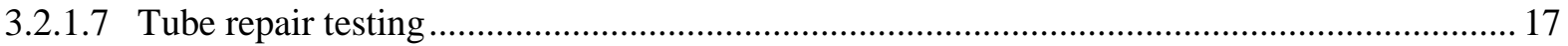

3.2.2 Panel Component Testing Assessment ..................................Error! Bookmark not defined.20

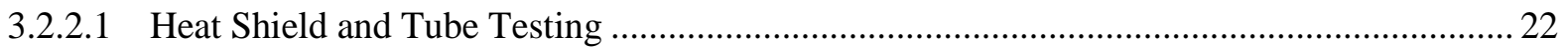

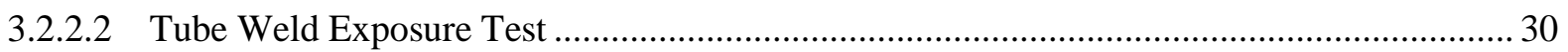

3.2.2.3 Tube Pyromark Paint Cure Test ....................................................................................... 33

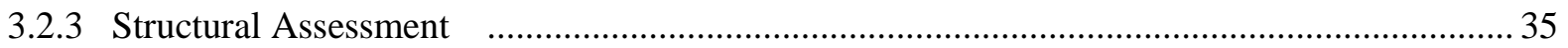

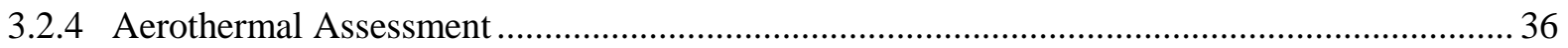

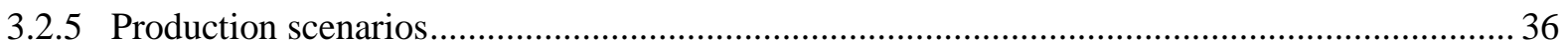

3.2.5.1 Cost Comparision to Full Scale Panel \& Path Forward ....................................................... 37

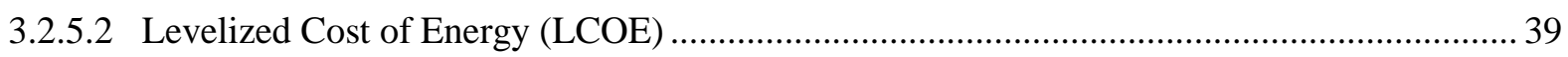

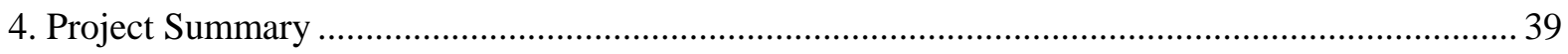




\section{PROJECT OBJECTIVES}

The objective of this project is to complete a design of an advanced concentrated solar panel and demonstrate the manufacturability of key components. Then confirm the operation of the key components under prototypic solar flux conditions. This work is an important step in reducing the levelized cost of energy (LCOE) from a central receiver solar power plant. The key technical risk to building larger power towers is building the larger receiver systems. Therefore, this proposed technology project includes the design of an advanced molten salt prototypic sub-scale receiver panel that can be utilized into a large receiver system. Then complete the fabrication and testing of key components of the receive design that will be used to validate the design.

\section{INTRODUCTION}

This project falls under the Department of Energy's (DOE) Solar Energy Technologies Program managed by the Office of Energy Efficiency and Renewable Energy. This project covers the design and construction of hardware that will be on-sun tested at The National Solar Thermal Test Facility (NSTTF) at Sandia National Laboratory. Sandia is recognized as the desired location for testing and collaboration for this project. The NSTTF is the most capable facility in the nation for testing receiver panels and has successfully tested several in the past for Pratt \& Whitney Rocketdyne (PWR).

This project shall have a significant impact on solar thermal power plant design. Receiver panels of suitable size for utility scale plants are a key element to a solar power tower plant. Many subtle and complex manufacturing processes are involved in producing a reliable, robust receiver panel. Given the substantial size difference between receiver panels manufactured in the past and those needed for large plant designs, the manufacture and demonstration on prototype receiver panel components with representative features of a full-sized panel will be important to improving the build process for commercial success. Given the thermal flux limitations of the test facility, the panel components cannot be rendered full size.

Significance changes occurred in the projects technical strategies from project initiation to the accomplishments described herein. The initial strategy was to define cost improvements for the receiver, design and build a scale prototype receiver and test, on sun, with a molten salt heat transport system. DOE had committed to constructing a molten salt heat transport loop to support receiver testing at the top of the NSTTF tower. Because of funding constraints this did not happen. A subsequent plan to test scale prototype receiver, off sun but at temperature, at a molten salt loop at ground level adjacent to the tower also had to be abandoned. Thus, no test facility existed for a molten salt receiver test. As a result, PWR completed the prototype receiver design and then fabricated key components for testing instead of fabricating the complete prototype receiver.

\section{PROJECT RESULTS}

A final panel design is complete including structural and thermal-fluid analyses and materials engineering as well as an evaluation of prototype panel issues. Detailed technical component specifications are 
complete. A Critical Design Review (CDR) was held on June $29^{\text {th }}, 2010$ at PWR where a board of experts was able to review the final design of the receiver.

\subsection{FINAL PANEL DESIGN SUMMARY}

A number of innovative design ideas have been developed. Key features of the receiver panel have been identified. This evaluation includes input from Solar 2, personal experience of people working on these programs and meetings with Sandia.

Common design tools have been implemented to evaluate the design improvements. These tools include trade studies to compare different design features, and parametric 3-D modeling (Pro-Engineer) created a visual concept of the design $\&$ was used for both structural $\&$ thermal analysis.

Key components of the receiver design and key processes used to fabricate a receiver have been selected for further evaluation. The heat shield system being one of the components selected that would require actual fabrication and on sun testing to test the effectiveness of protecting sensitive components from solar spillage from the heliostats. Section 3.2 describes the manufacturing feasibility and results of onsun testing performed at Sandia National Lab.

\subsection{TEST PLAN SUMMARY}

The Test Plan, Concentrated Solar Power Receiver In Cooperation with the Department of Energy and Sandia National Laboratory (version 4) was written to define the scope of the testing to be completed as well as to provide a reference for details related to the hardware, instrumentation, and data acquisition. The document contains a list of test objectives, a test matrix, and an associated test box showing the operating points to be tested.

Test Objectives:

1. Demonstrate low-cost manufacturability

2. Demonstrate robustness of two different tube base materials

3. Collect temperature data during on sun operation

4. Demonstrate long term repeated daily operation of heat shields

5. Complete pinhole tube weld repairs

6. Anchor thermal models

The test plan also has descriptions of the various components of the receiver to provide a quick reference to personnel at the test facility. Additionally, the test plan and associated documents have assembly instructions as well as detailed information about the instrumentation and data acquisition. The instrumentation on the receiver components consists of numerous thermocouples and flux gages. The thermocouples measure the temperature throughout the components. The flux gage measures the solar flux contacting the receiver components. The instrumentation list, instrumentation diagram and data acquisition requirements allow the facility to provide a data acquisition system that performs as needed for the testing of the receiver. This aids PWR with the post-test data analysis and allows for quantification of the benefits of PWR's cost saving approach to designing this receiver.

The system for this project includes both the PWR test articles (tubes and heat shields) as well as the NSTTF solar power tower. Both test articles were attached to the top of the tower at SNL for testing. They were rolled to the edge of the tower for testing and then back to the middle of the top of the tower for inspections and any work that would need to be performed on them. No salt loop is required for this testing. 


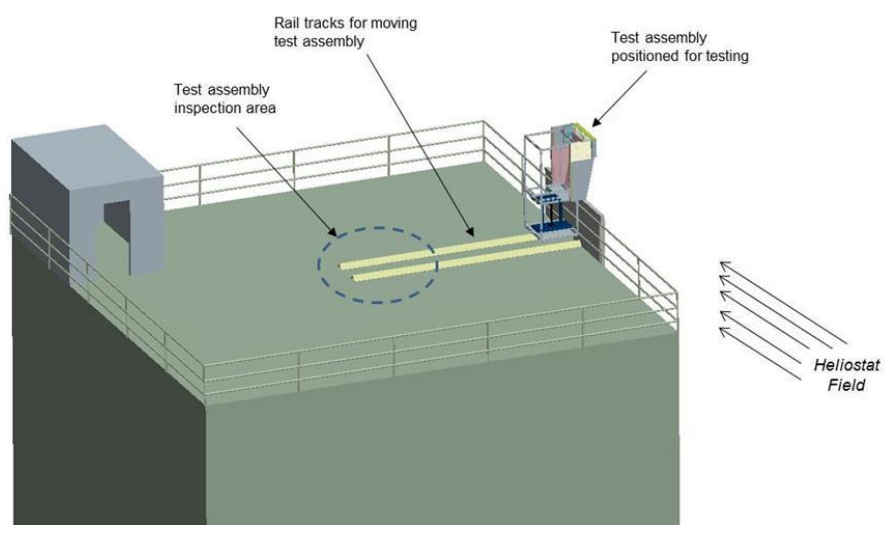

Testing on top of Tower

\subsubsection{PANEL COMPONENT FABRICATION ASSESSMENT}

A manufacturability assessment has been performed on key components of a receiver. This includes (3) different heat shields designs, clip support assembly, tube clip. The heat shields were tested under actual solar conditions. A weld repair method for repairing small pins holes in receiver tubes has been developed and tested.

\subsubsection{Key Suppliers}

All key suppliers are new to the CSP industry and have expressed great interest in becoming a part of the solar industry now and in the future.

\subsubsection{Heat Shield Assembly}

There are three different heat shield configurations that have been fabricated and tested. The double layer heat shield uses two layers of high temperature composite board material with an air gap between the layers. The front and side shield use commercial grade stainless steel sheet and the side shields use a low cost ridged insulation. 


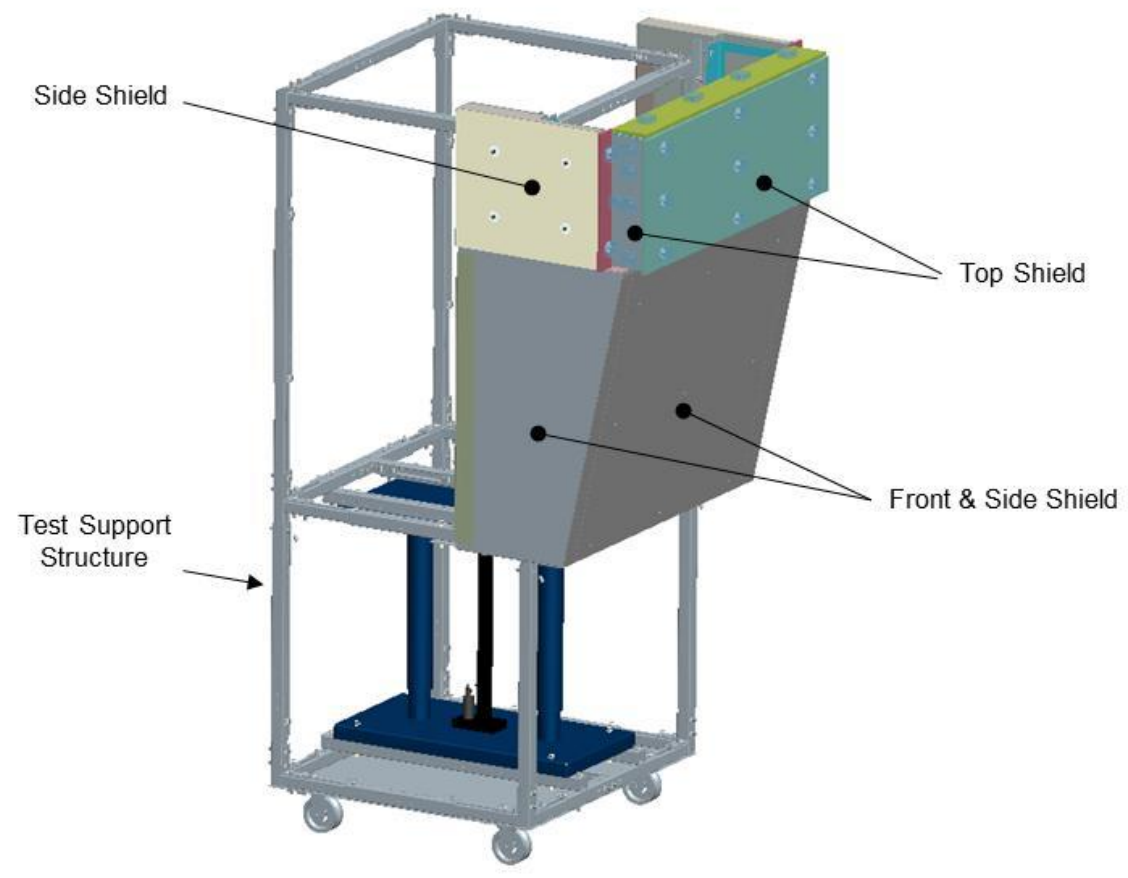

Heat Shield Test Assembly

The panels on the front of the receiver will receive the largest amount of solar flux. Because of the high heat flux, these shields are located adjacent to the receiver tubes flowing molten salt. In order to reduce the impact of the high temperatures a double layer of high temperature composite board was used, with each layer being separated by an air gap. This drastically reduces the temperature that reaches the sheet metal structure. 


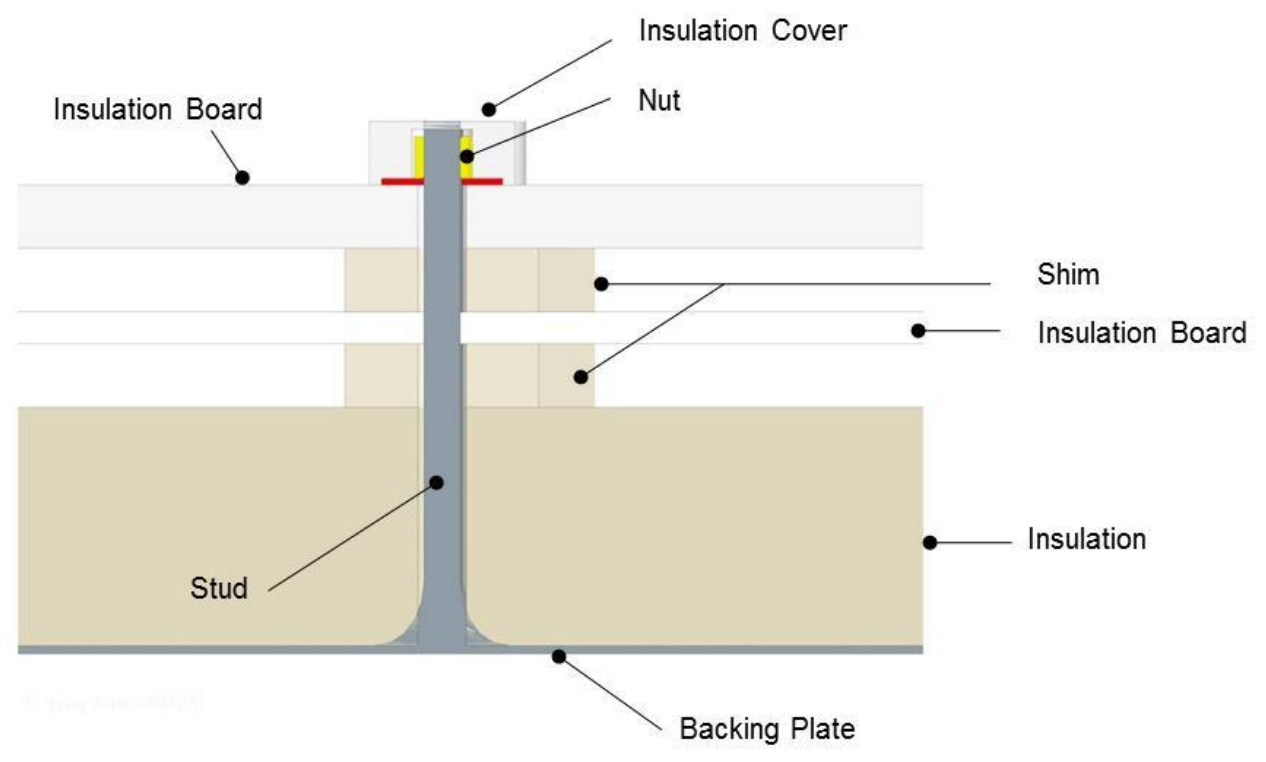

HEAT SHIELDS

High temperature composite board material was used for these heat shields that will be exposed to the highest temperatures. The material is resistant to thermal shock with a very low thermal expansion rate $\left(0.3 \times 10^{-} 6\right)$ and can work in temperatures up to $3,000^{\circ} \mathrm{F}$. The material is also resistant to an outside environment and it should easily survive 30 years of service without maintenance or replacement. During assembly operation the panels have been very easy to work with. The high temperature composite board is commercially available and is easily fabricated into intricate shapes. Even though the fabrication requires dust prevention methods, the material can be machined using common manufacturing tools. The cost of 1/4" thick refractory sheet material is less than half the cost of a similar size piece of 321 stainless, and a similar size piece of 625 nickel alloy would be about 4 times above that amount. The cost of manufacturing either of these materials would be the comparable since the same processes would be used. 


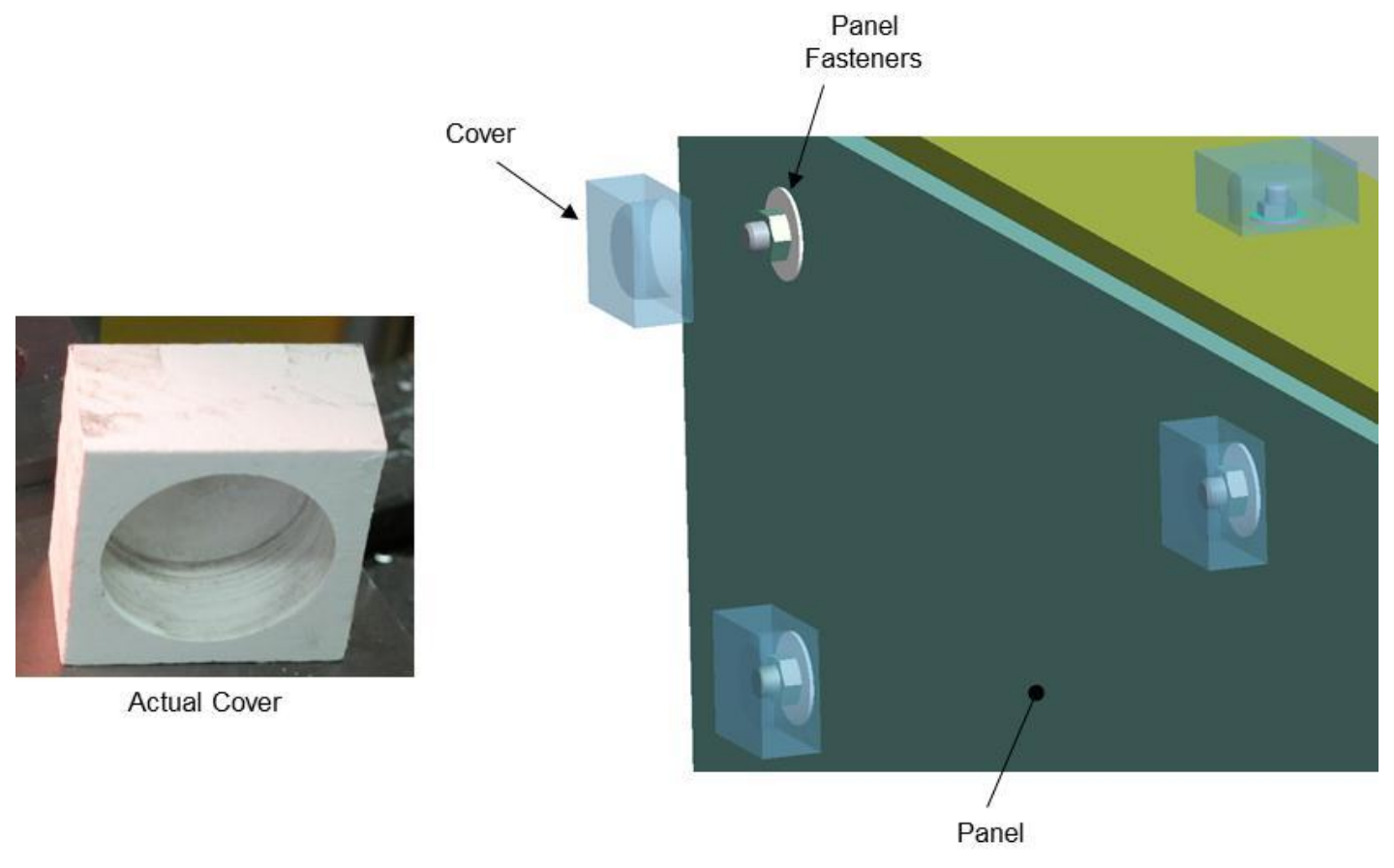

HEAT SHIELDS

Covers are installed over the fasteners that secure the panels. This protects the fastener hardware from the high solar flux. The covers are made from the same material as used on the panels. High temperature adhesive is used to hold the covers to the panels. This adhesive has a low expansion rate, sets up in minutes, is thermal shock resistant and has excellent adhesion properties. 


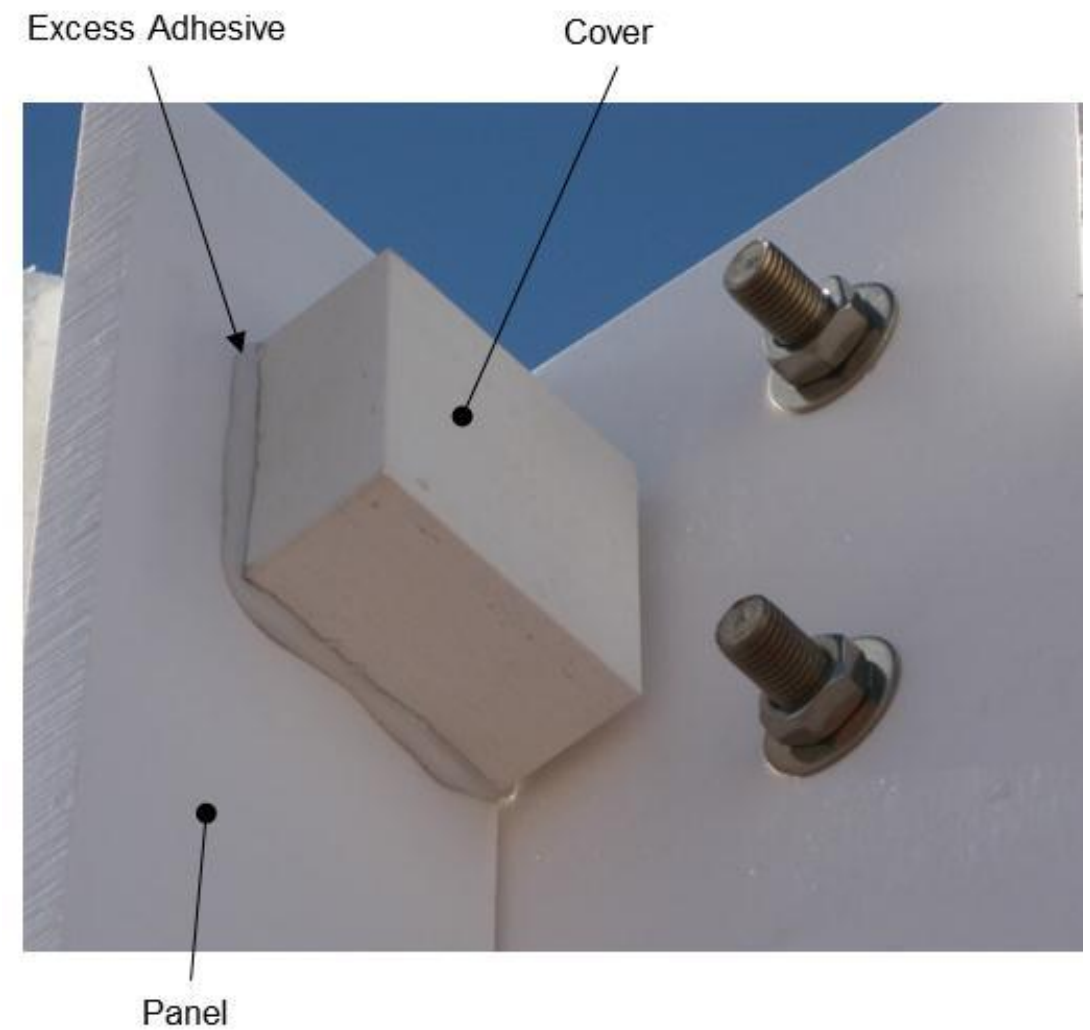

HEAT SHIELDS

Applying the adhesive was tested on pieces of high temperature composite board material. The application lab tests showed that the high temperature composite board quickly draws the moisture out of the adhesive. The best practice is to apply a thin coat to each surface to be adhered then quickly scrap off any excess. Once that sets up, then apply a layer of adhesive about $1 / 32$ thick on both surfaces and install the two surface together. Any excess adhesive material was left on the adhesion joint. It was suggested that the excess adhesive material be formed into a fillet shape for added strength but this was never demonstrated. The covers set up at outside temperature $\left(\sim 65^{\circ} \mathrm{F}\right)$ for approximately 4 hours. Adhesive instructions said that the cure time could be accelerated by applying heat at $175^{\circ} \mathrm{F}$ for 5 minutes. However the test did not demonstrate this acceleration method. During operation the high temperature adhesive is good up to $2,500^{\circ} \mathrm{F}$. This is much higher than the expected temperatures on the surface of the high temperature composite board. 
There is one panel on the front of the test setup and a side panel on each side of the test setup. The front and side shields fabricated with a commercial grade stainless steel. The material can be easily formed to any configuration. Bolts are threaded through the sheet metal to fasten soft insulation on the backside of the sheet metal. Speed nuts are installed on the threaded studs to hold the insulation panels in place. The speed nuts allow easy removal of the insulation panels. The sheet metal can work in environments around $1,700^{\circ} \mathrm{F}$ and the insulation behind the sheet metal will protect the support structure from the heat. The sheet metal is painted with a very thin coat of commercially available white paint to further reflex any solar spillage on the shields. A white paint was used. This paint is heat resistant up $2000^{\circ} \mathrm{F}$ and is normally used for high temperature applications in the auto industry.

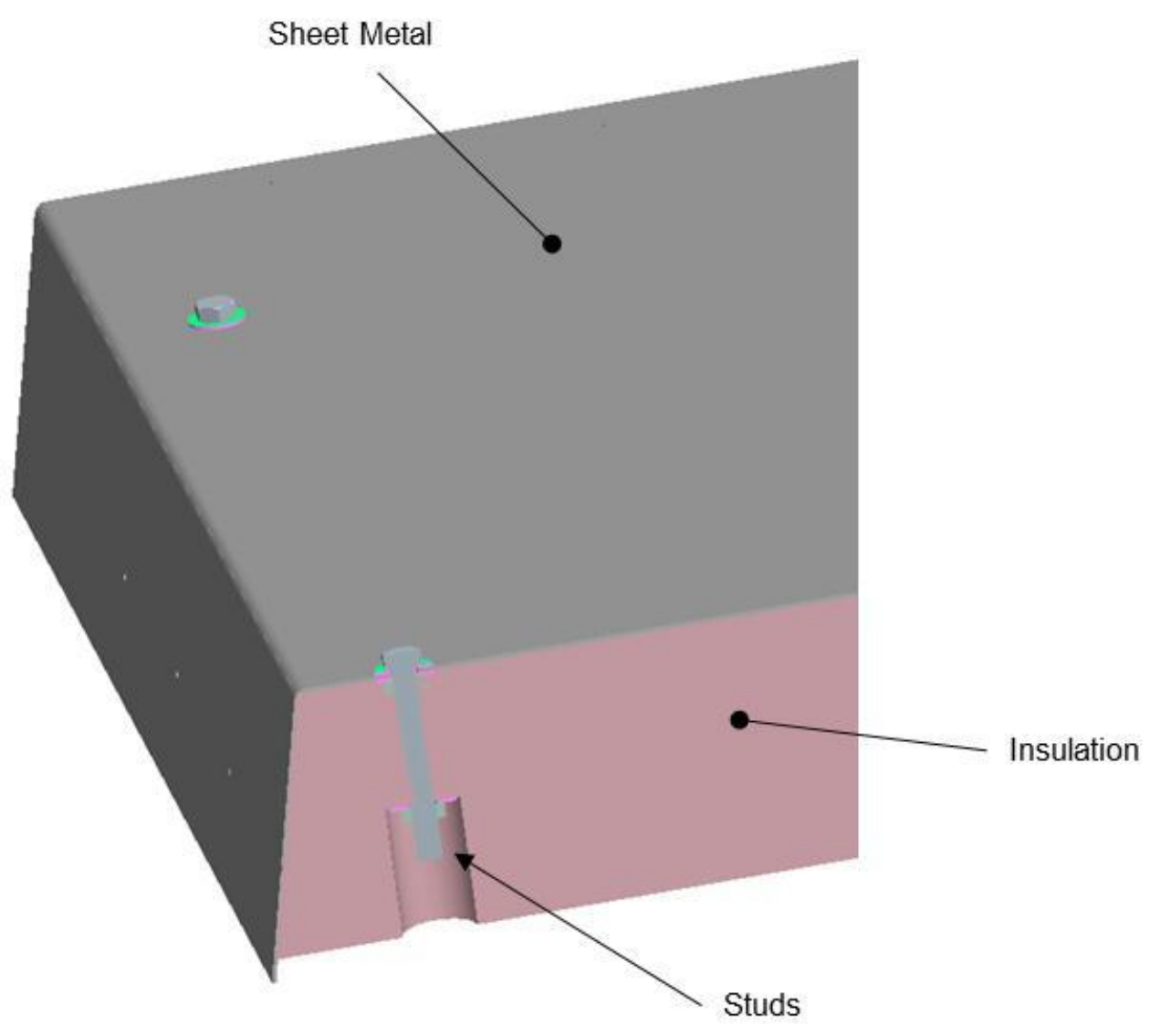

Front and Side Heat Shields 


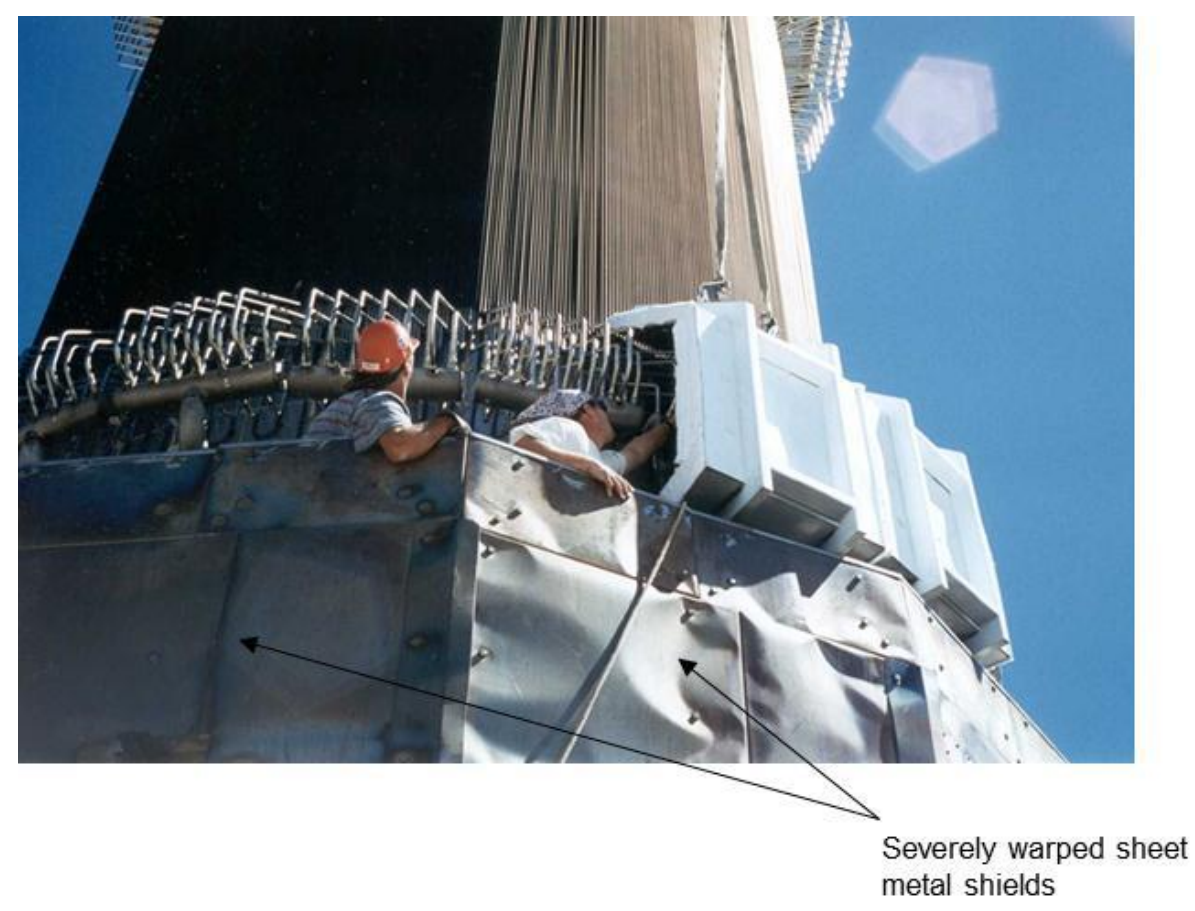

SOLAR 2 HEAT SHIELDS

The purpose of these sheet metal heat shields is to demonstrate that a commercial grade sheet metal shield, painted with common commercial grade paint can withstand the harsh environment of a CSP plant. Past experience showed that uncoated sheet metal will be damaged by the hot temperatures. The sheet metal shields on Solar 2 had been damaged and warped by the solar spillage. This allowed a heat leak making it difficult to start up the receiver system in the morning when trace heaters on the tubes and headers attempt to bring the system up to the minimum temperature of $550^{\circ} \mathrm{F}$ so molten salt can flow through the system. Local areas of the tubes with any cold spots would cause the salt to freeze, plugging the system and preventing plant operation.

The side shields are used to protect the side areas from solar spillage. High density insulation covers a softer insulation module and also acts as an insulator. The high density insulation is better at resisting the outdoor environment and protects the internal insulation that is more susceptible to moisture. The panels are attached with threaded studs that were stud welded to a sheet metal supporting structure. 


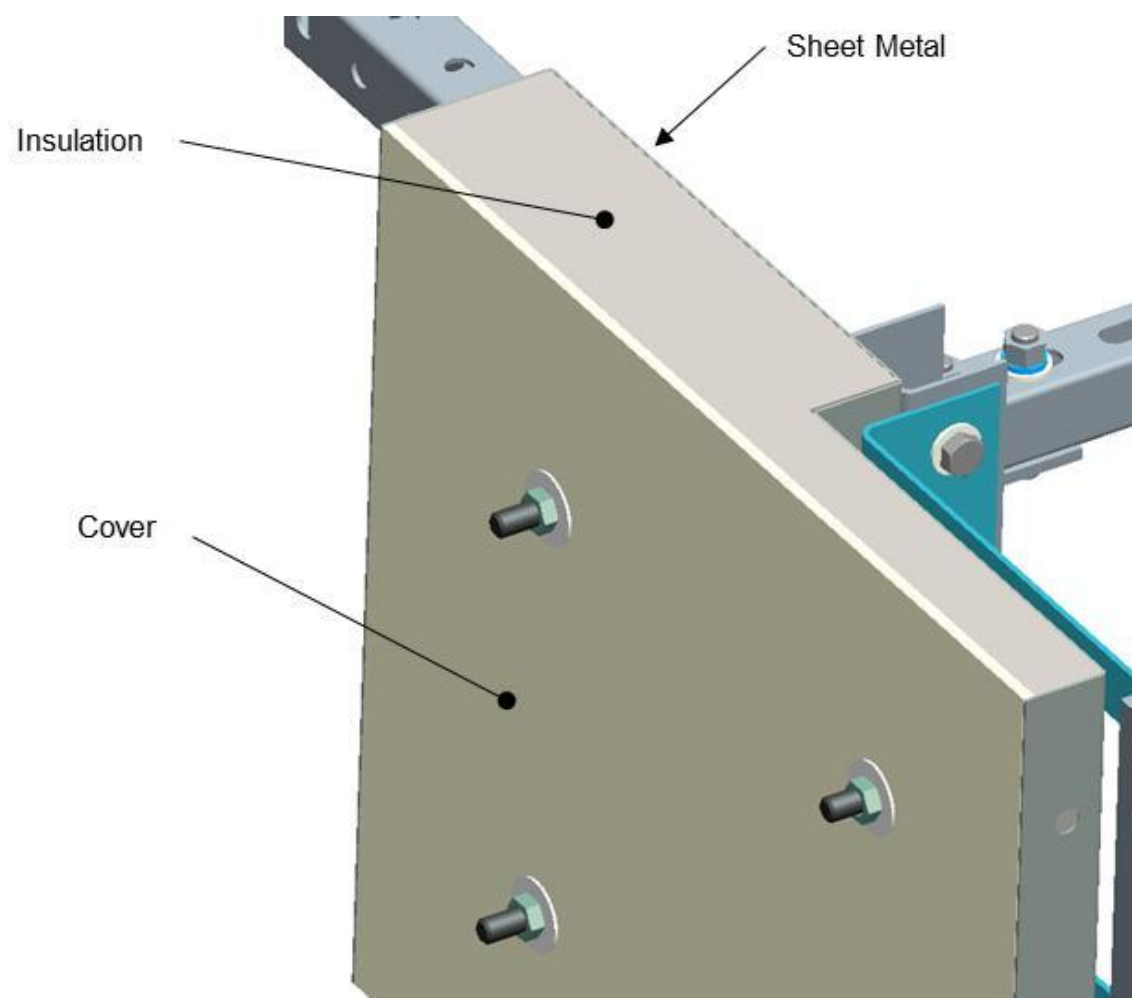

SIDE SHIELDS

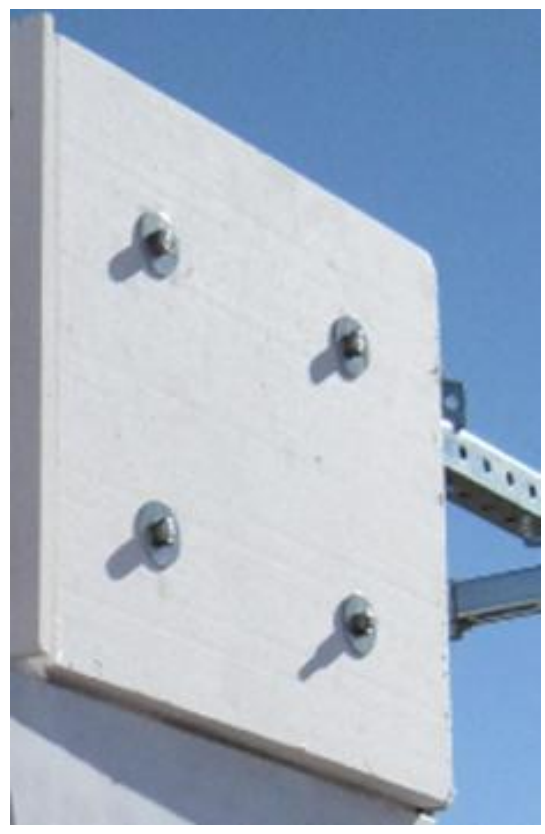

ACTUAL SIDE SHIELD 
A $1 / 4$ " thick high density insulation was used. However during assembly operation the $1 / 4$ " thick board proved to be too fragile and was damaged. The thinner board was replaced with a 1" thick piece. This proved to be a better choice. The high density insulation is a commonly used product in insulation field and is readily available. It is a low cost rigid high temperature alumina-silica insulation board that can work in temperatures up to $2,300^{\circ} \mathrm{F}$.

\subsubsection{One Piece Tube Clips}

Tube clips are welded to the tubes and are used to guide the tubes along the axis of the tube as the tubes thermally expand and contract during operation. The current two piece tube clip configuration is fabricated using a machined sheet metal piece and a piece of tube stock. The 2 pieces are welded together and the weld is inspected using NDT requirements. The heat affected zone of the weld can cause some distortion to the two piece clip assembly. The new one piece clip is formed from one piece of sheet metal in one operation. No welding or weld inspection is required. Ten, one piece clips, have been fabricated. No anomalies have been noted during inspection. The cost is relatively high at but economies of scale will substantially reduce the cost when applied to a CSP production plant order. It is estimated that a typical CSP plant would require approximately 10,000 tube clips.



Current Two Piece Tube Clip

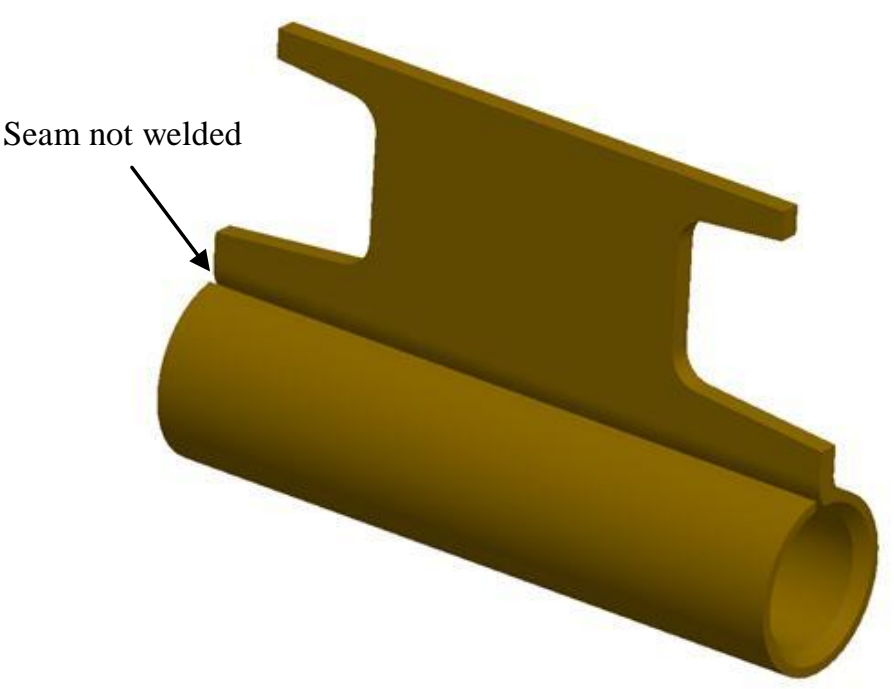

New One Piece Tube Clip

\subsubsection{Laser Weld Clip to Tube}

Clips are welded to the tubes and are used to guide the tubes along the axis of the tube as the tubes thermally expand and contract during operation. Currently a manual or automatic GTAW type of weld is 
used to attach the clip to the tube. The tube wall thickness being thin it makes it difficult to weld. The team evaluated using a laser welding machine to weld the clips on. A metal fabricator was selected to evaluate using a laser process for this configuration. After welding a number of weld samples using their 150 watt laser welder. They noted that their equipment was not powerful enough to weld the clip to tube configuration. They suggested using a 300 watt system. PWR searched for a supplier with such equipment to no avail. This type of welder is specialized and not commonly used in industry. No further evaluation of the laser weld process was performed.

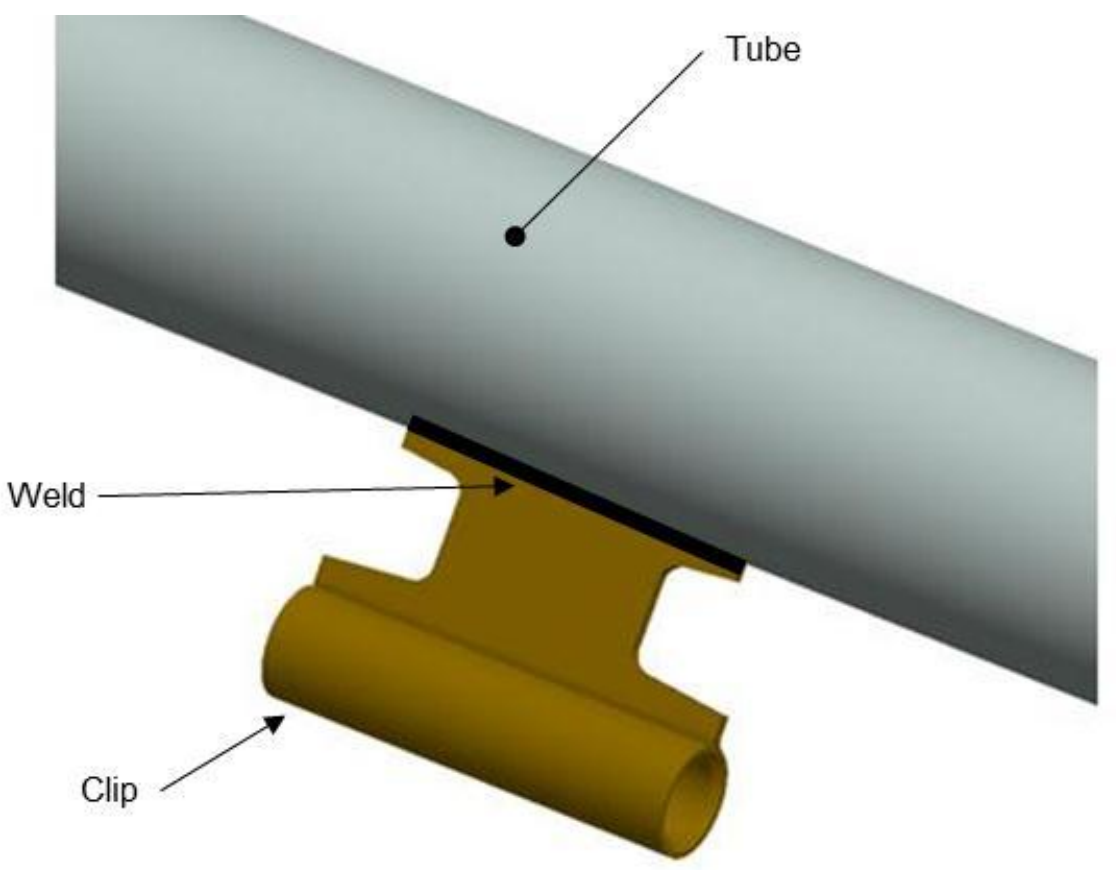

Clip to Tube Weld

\subsubsection{Header with Welded In Stubouts}

The nozzle stubouts are machined individually and welded into holes machined into the header.

Currently the header stubouts are formed integral to the header during processing. The team wanted to evaluate using a laser welding machine to weld the nozzle stubouts into the header. This is because the 
laser weld process will introduce less heat into the weld. This may cause more distortion to the header. After welding a number of weld samples using a 150 watt laser welder. It was discovered that the equipment was not powerful enough to weld the clip to tube configuration. This is similar to the issue note on the clip to tube weld. PWR searched for a supplier with a 300 watt system to no avail. This type of welder is specialized and not commonly used in industry. The cost to purchase such a machine would be too high. No further evaluation of the laser weld process was performed. Testing the manual weld process would require a full size header to demonstrate and it was not cost effective.

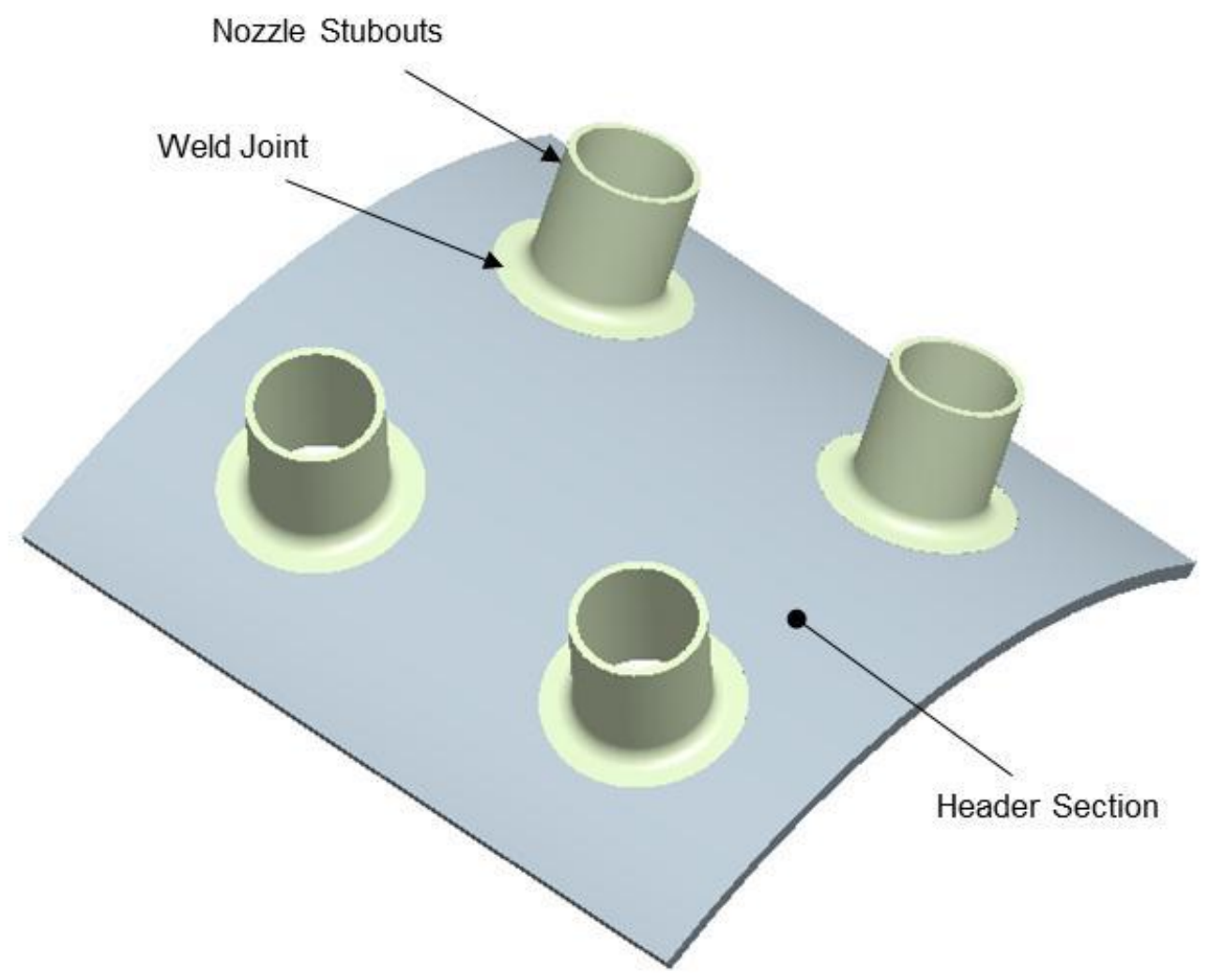

\section{Header Test Weld}

\subsubsection{Tube Support Clip System}

During operation, the receiver tubes thermally expand and contract, mainly along the axis of the tube. The clip assembly controls the movement of the tube along its axis and prevents distortion and bending of the tube out of the plane of the panel. The goal is to design a robust tube support system that could be easily fabricated. A fabricator was able to fabricate one assembly to meet all drawing requirements. 
The new clip support assembly design emphasizes common low cost fabrication processes that will adequately allow the tubes to thermally expand along the tube axis in this high temperature environment. The support bracket starts from single piece of flat sheet stock that is cut using a water jet cutting process and is then formed to final shape. Guide rods slide in and are bolted on both ends. The guide rods are easily removed to facilitate any individual tube that may need to be replaced on a full size receiver. The number of detail parts in the clip assembly is reduced by $40 \%$. The cost of one assembly was relatively high but large numbers would make this design feasible in a production order. A typical CSP plant would require approximately 140 clip support assemblies.

\subsubsection{TUBE REPAIR TESTING}

The purpose of this experiment is to demonstrate that a pin hole leak on a receiver tube can be adequately be repaired until scheduled maintenance can replace the receiver tube. Currently weld repairs of receiver tubes are not allowed. The receiver panel is removed from service and replaced with a new receiver panel. The damaged tube is completely removed and replaced with a new tube. The concern is that a locally damaged tube with a small leak would be difficult to weld. The inside diameter of the tube would contain salt residue that would be difficult to remove. Also the tube configuration would make it difficult to back purge. The effects of the salt residue and lack of inert gas backpressure on the quality of the weld is difficult to predict without experience. This has led to an experiment in welding tubes that have been exposed to molten salt without the use of backpressure. The experiment was completed at PWR's weld lab.

The inside surfaces of two tubes sections, approximately 12 " in length, were exposed to molten salt at $1050^{\circ} \mathrm{F}$ for 252 hours. This is the operating temperature of a Molten Salt CSP Plant. The salt was drained from the tubes leaving behind a residual layer of salt that would be present in a typical CSP receiver tube.

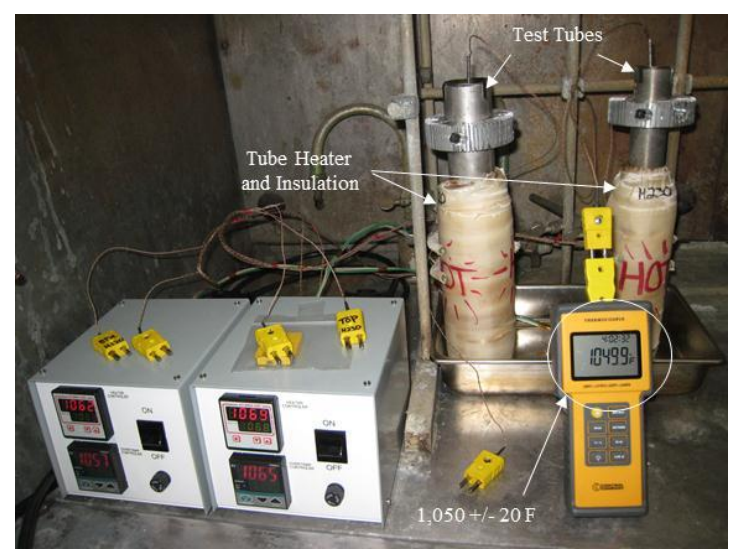

Molten Salt Exposure within Tubes

The weld lab drilled a small diameter hole through one wall on each tube sample. This simulated a pinhole leak that may occur to a receiver tube out in the field. The weld engineer was not allowed to clean or prep the inside diameter of the tube. Again this is to simulate actual conditions in the field. One tube sample was prepped using "Bathtub" weld prep while the other tube received no weld prep.

The holes in both tubes were weld filled with filler material. The tube was placed in a horizontal position along the axis of the tube and the axis of the hole was in a vertical position with the hole on top. No 
purge of the inside of the tube. The "as-welded" welds passed both visual and face side surface penetrant inspection.

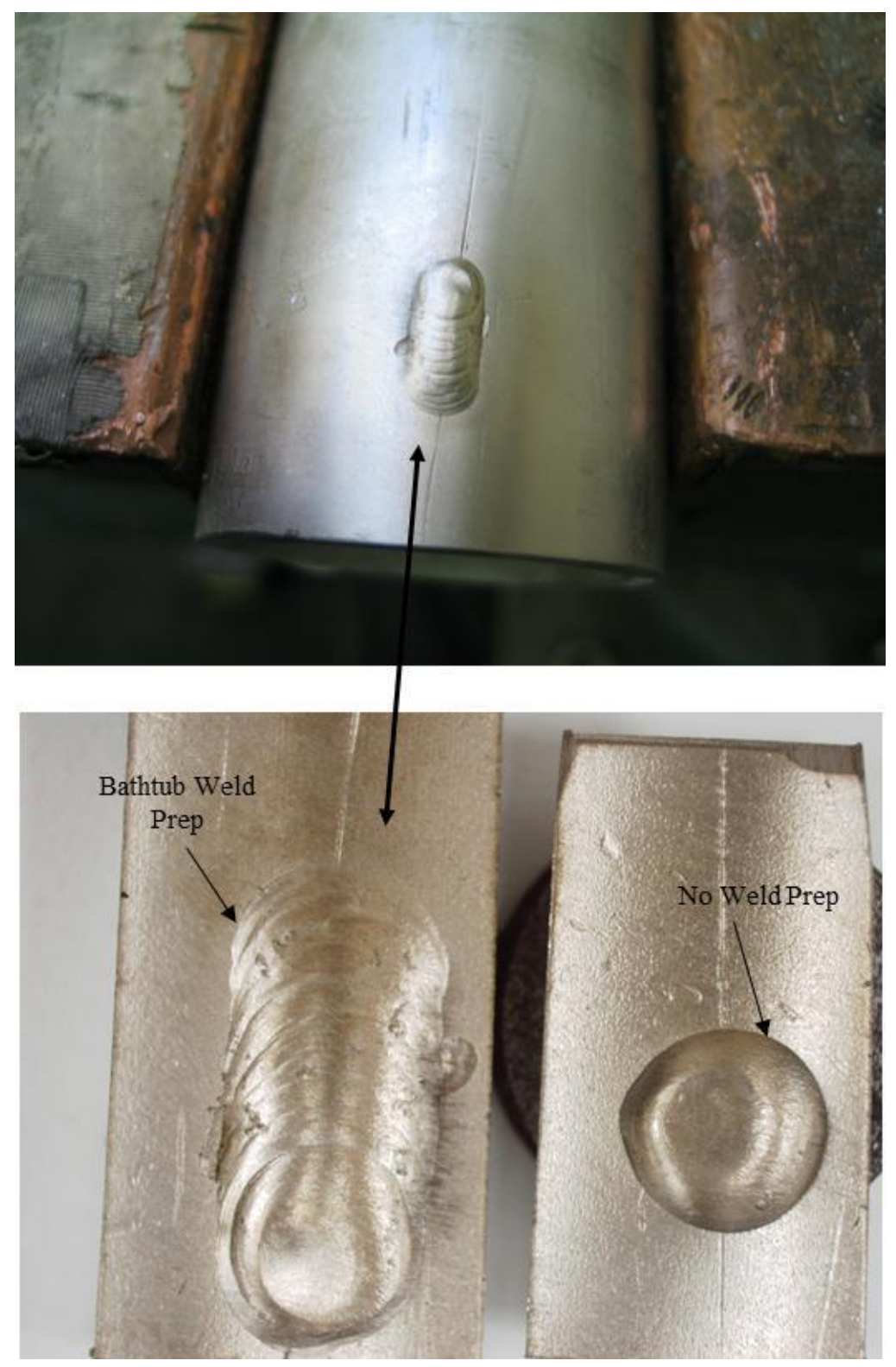

\section{As Welded Welds}




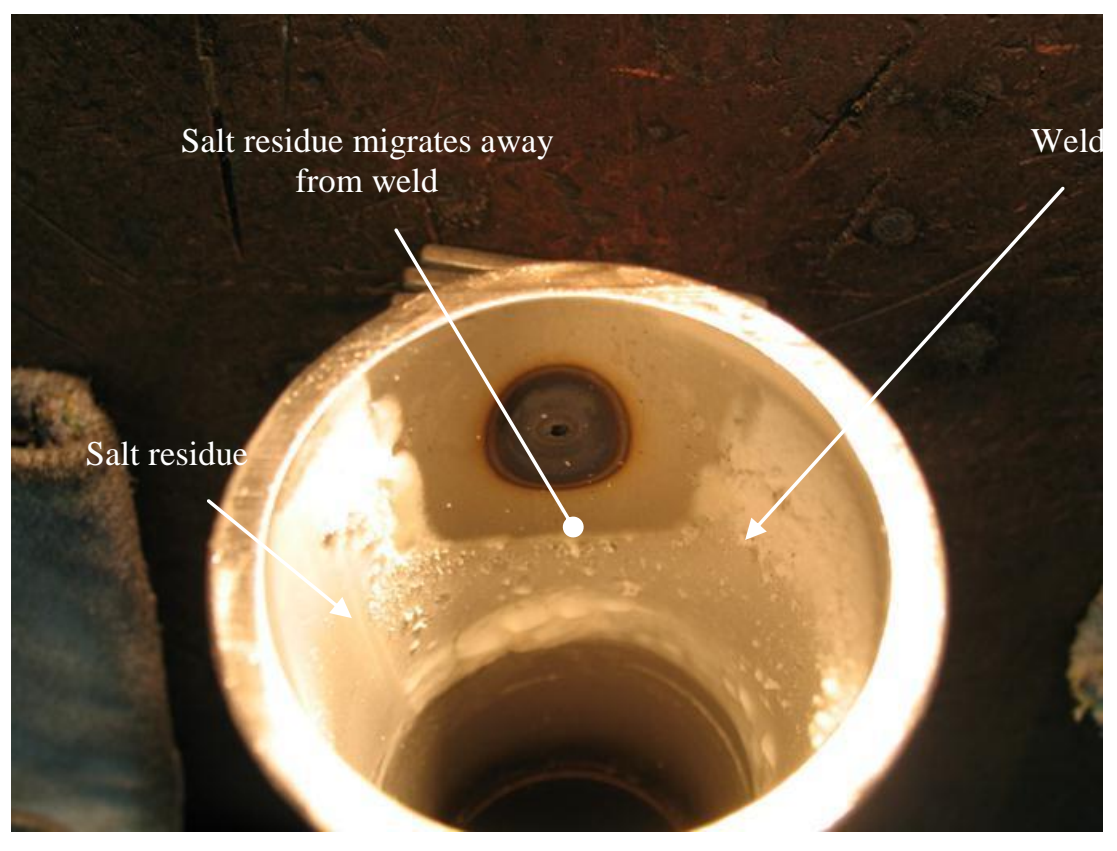

Backside of Weld, Welded in a Horizontal Position

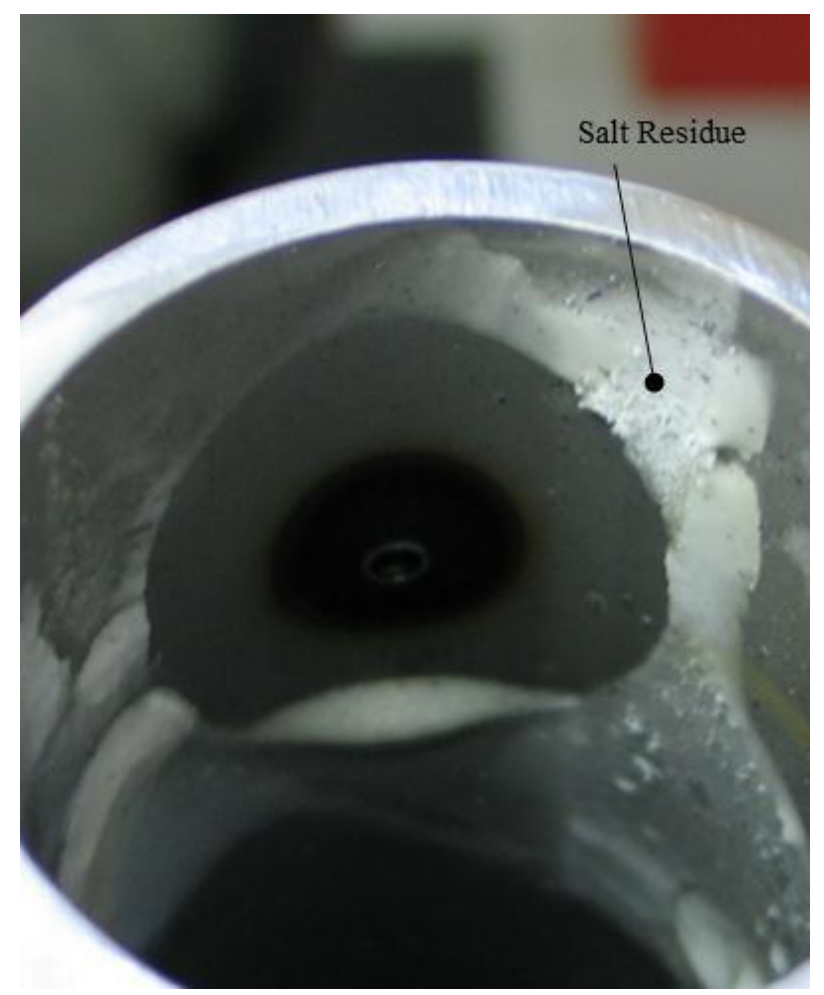

Backside of Weld, Welded in a Vertical Position 
The first weld joint was welded in a horizontal position. The salt residue melted away from the root of the weld. No negative impact to the weld joint was noted. An additional test was performed to weld the tubes in a vertical position. Again the salt residue melted away from the root of the weld. The welds were then sectioned to visually verify the integrity of the weld. Concavity at the root of the weld joint was noted. This is due to the lack of a purge on the backside of the weld (inside diameter of the tube. No purge was used because a purge would not be possible in a repair of a tube in the field.

The conclusion is that a pinhole leak in a receiver tube can be temporally repaired until a scheduled maintenance can replace the complete tube. Weld parameters would need further development to optimize the weld. Further evaluation of the weld repair would be required to more accurately determine the actual life expectancy of the weld repair. Initial structural assessment shows that this weld could last for 6 months of CSP plant operation. This should be adequate time to schedule maintenance to replace the damaged tube with the least impact on plant operation.

\subsubsection{PANEL COMPONENT TESTING ASSESSMENT}

Key components of the receiver heat shields have been fabricated, shipped to Sandia National Lab CSP Test Facility and assembled for testing under actual solar conditions. Thermal couples have been installed in specific areas note in the test plan. Solar flux gauges have also been installed to measure the amount of solar flux reaching the heat shields. Thirteen tests were performed on the heat shields. The solar flux started at $50 \mathrm{~kW} / \mathrm{m}^{\wedge} 2$ and increased with each test until the solar flux reached $500 \mathrm{~kW} / \mathrm{m}^{\wedge} 2$. This included two tests to test the impact of rain on the heat shields. The heat shields were soaked with water just prior to a $300 \mathrm{~kW} / \mathrm{m}^{\wedge} 2$ test. This test demonstrated how well the heat shields will do after a rain shower and whether the receiver could be brought back on line immediately or whether a drying process would be required. An additional test was performed at a solar flux level of $625 \mathrm{~kW} / \mathrm{m}^{\wedge} 2$. This was performed to test the limits of the heat shields.

The salt freeze and thaw test listed in the test plan was not performed (Tube Test \#5). After discussing the test plan with the Sandia test engineers, it was determined that this test could potentially crack tubes and the molten salt could cause collateral damage to the test assembly. The short tubes (24") would limit the target area for the heliostat to focus on and the tube holder was not design to hold longer tubes. The team decided that the limited amount of potential information from this test is not worth to the damage that may occur.

There were also four tests that expose tubes that have been welded. The tubes were exposed to solar flux that brings the temperatures of the tubes up to operation temperatures $\left(1050^{\circ} \mathrm{F}\right)$. The welds were then be evaluated to check the impact of the flux on the tube weld joints. Currently no welds are allowed in the sun lit area of the tubes. This could lead to lower cost standard length tubes being welded instead of using specially fabricated longer tubes. 


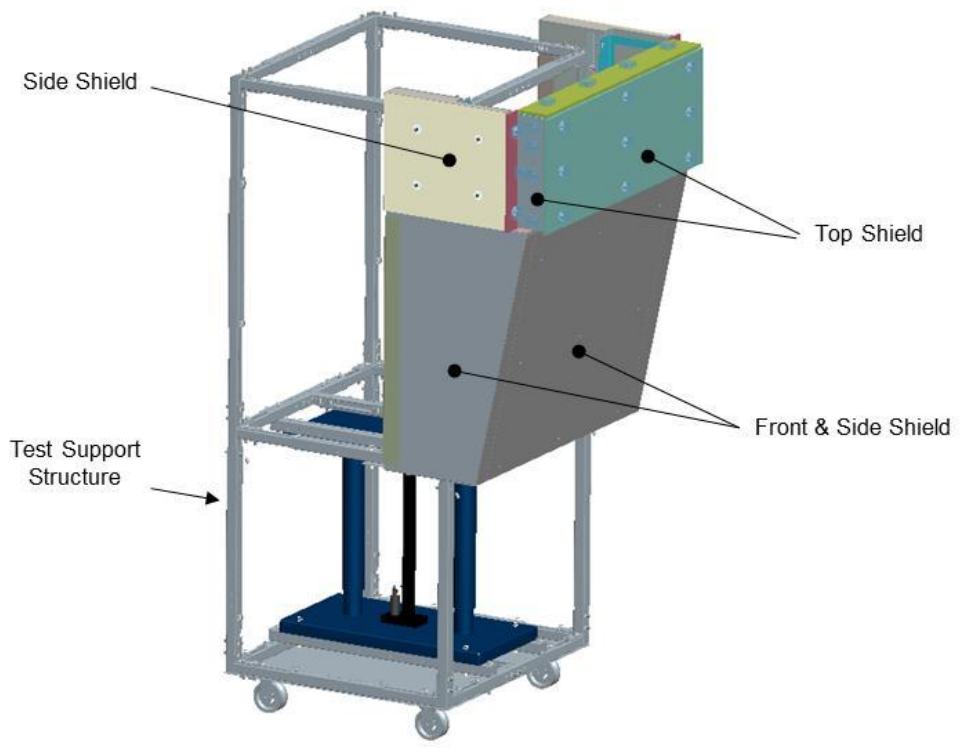

Heat Shield Test Assembly

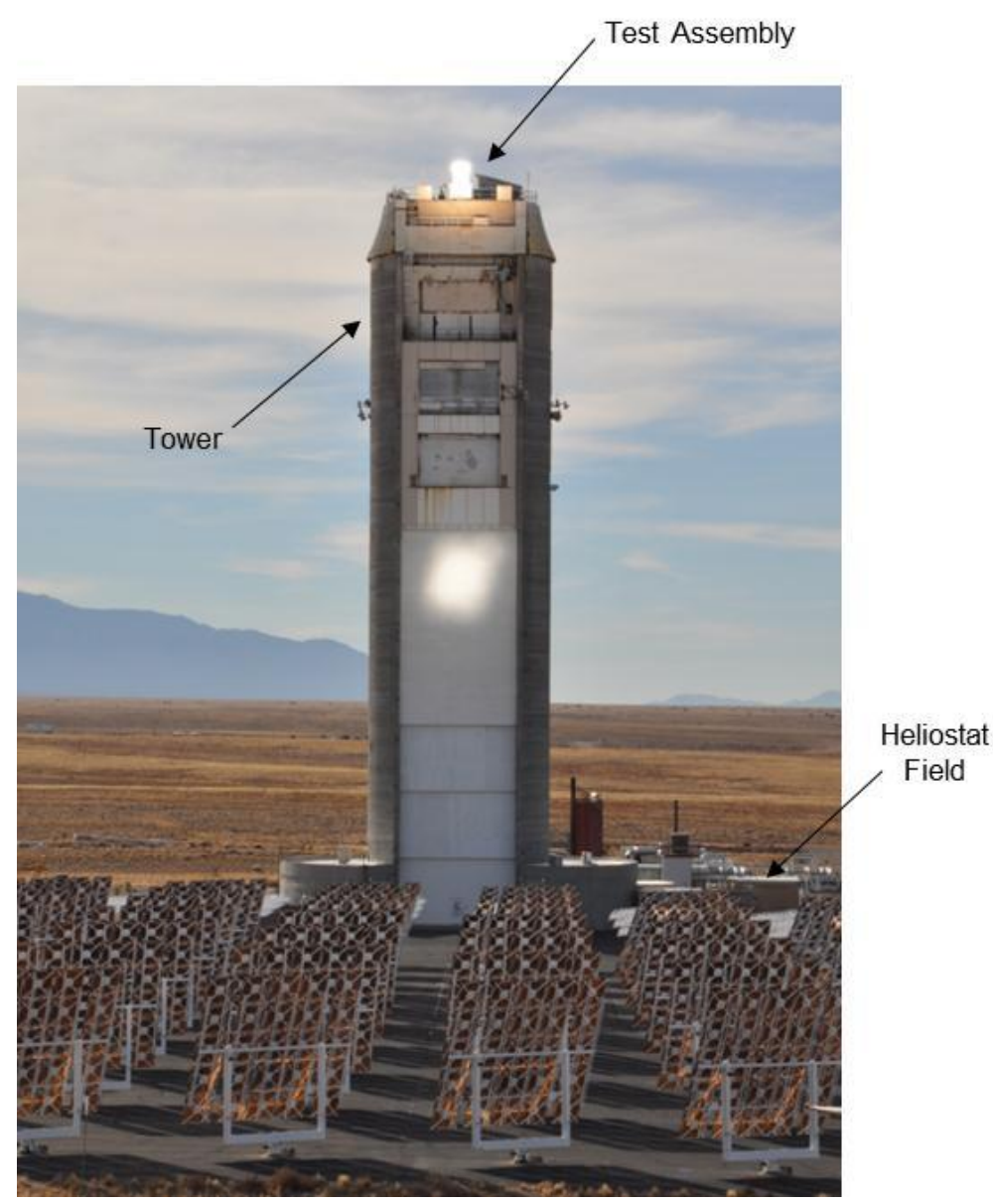

Actual Testing on top of Tower at Sandia 


\subsubsection{HEAT SHIELD AND TUBE TESTING}

The test plan describes various key components of a receiver panel that can be tested at the Sandia test facility. The testing include on sun testing of heat shields, welded tube and a paint cure test. A test plan was created giving a description of each tests requirement. The test plan has assembly instructions as well as detailed information about the instrumentation and data acquisition. The instrumentation on the receiver components consists of numerous thermocouples and flux gages. The thermocouples measure the temperature throughout the components. The flux gage measures the solar flux contacting the receiver components. The system for this project includes both the PWR test articles (tubes and heat shields) as well as the Sandia test facility. All test articles were attached to the top of the tower at Sandia for testing. They were able to be rolled to the edge of the tower for testing and then back to the middle of the top of the tower for inspections and any work that would need to be performed on them. No salt loop is required for this testing. The details of the testing are described in section 3.2.2.1.1 thru section 3.2.2.1.3. Note that Tube Tests 1, 3, $4 \& 5$ have been performed in sequence then Tube Test 2 was performed.

\begin{tabular}{|c|c|l|c|c|}
\hline Test Phase & Test \# & \multicolumn{1}{|c|}{ Test Description } & $\begin{array}{c}\text { Average Heat } \\
\text { Flux on Heat } \\
\text { Shield (kW/m²) }\end{array}$ & $\begin{array}{c}\text { Est. Length of } \\
\text { Test (Hours) }\end{array}$ \\
\hline Heat Shield & 1 & Instrumentation Checkouts & 50 & 1 \\
\hline Heat Shield & 2 & Operation Range - 50 Suns & 50 & 1 \\
\hline Heat Shield & 3 & Operation Range - 100 Suns & 100 & 1 \\
\hline Heat Shield & 4 & Operation Range - 150 Suns & 150 & 1 \\
\hline Heat Shield & 5 & Operation Range - 200 Suns & 200 & 1 \\
\hline Heat Shield & 6 & Operation Range - 250 Suns & 250 & 1 \\
\hline Heat Shield & 7 & Operation Range - 300 Suns & 300 & 1 \\
\hline Heat Shield & 8 & Water Soak Test - 300 Suns & 300 & 1 \\
\hline Heat Shield & 9 & Water Soak Test - 300 Suns & 300 & 1 \\
\hline Heat Shield & 10 & Extreme Temp Test - 350 Suns & 350 & 1 \\
\hline Heat Shield & 11 & Extreme Temp Test - 400 Suns & 400 & 1 \\
\hline Heat Shield & 12 & Extreme Temp Test - 450 Suns & 500 & 1 \\
\hline Heat Shield & 13 & Extreme Temp Test - 500 Suns & NA & 4 \\
\hline Tube & 1 & Instrumentation Checkouts (1,050F) & NA & 1 \\
\hline Tube & 2 & Paint Curing (Stepped Temps) & NA & 1 \\
\hline Tube & 3 & Stress Weld Joints (1,050F) & NA & 1 \\
\hline Tube & 4 & Repeat Stress of Weld Joints (1,050F) & NA & 1 \\
\hline Tube & 5 & Repeat Stress of Weld Joints (1,050F) & & 1 \\
\hline
\end{tabular}

\section{Test Matrix}

\section{Instrumentation:}

During the heat shield testing, the test article was outfitted with 62 thermocouples and two heat flux gauges. The thermocouples were installed on both the front and sides of the shielding and at different depths into the insulation. One heat flux gauge was located on top of the panel at the center of the test article and the second was located approximately at the center of the front shield. A data acquisition system (DACS) collected all the instrumentation data and directed the raw data to a computed where Lab View was used to convert the data into information. 


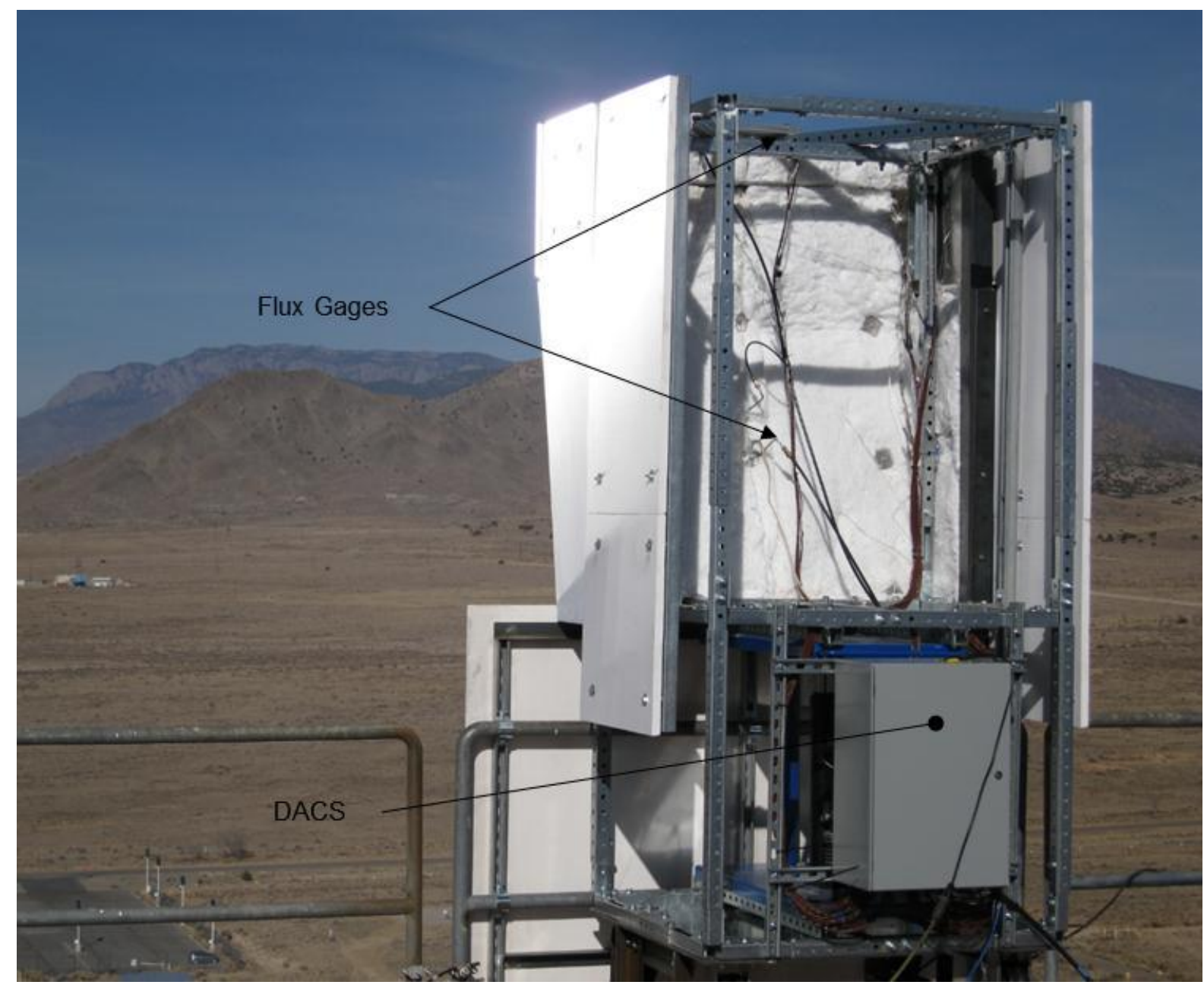

Flux Gage and Data Acquisition System Locations

\subsection{HEAT SHIELD TEST}

The purpose of the heat shields is to protect the internal surfaces of the receiver from the solar spillage that occurs during CSP plant during operation. Innovative designs can be used to reduce the fabrication costs and extend the life of the hardware. The solar testing at Sandia was performed in a ramp up fashion with initial lower level tests being performed to identify any workmanship issues or obvious issues with the design. The higher level testing was used to prove out the design for future longer duration testing or implementation on future solar towers. The testing sequence began with an instrumentation checkout at 50 suns $\left(50 \mathrm{~kW} / \mathrm{m}^{2)}\right.$. The testing then progressed to 500 suns or $500 \mathrm{~kW} / \mathrm{m}^{2}$ with the following test sequence, 50 suns, 100 suns, 150 suns, repeat of the 150 sun test, 200 suns, 250 suns, 300 suns, 300 suns with a water soak prior to test, repeat of the 300 suns with a water soak test, 350 suns, 400 suns, 450 suns, concluding with the $>500$ sun test.

\section{Test \#1- 50 System Checkouts}


The initial testing (50 suns) was performed by bringing on the heliostats (5) to the tower at 10 minute intervals. The heliostats were targeted at the top heat flux gage, which was approximately 2 inches above the panel. The instrumentation checkout showed that all of the TCs were functioning and that there was a lag for the internal sensors due to the insulation. There was a fair amount of smoke / outgassing coming from the insulation between the high temperature composite board and the structure. The peak temperatures were shown at the front, metal shield. The heliostats were brought off the tower in approximately 3 minute intervals. There were no noticeable changes to the structure or insulation after the testing.

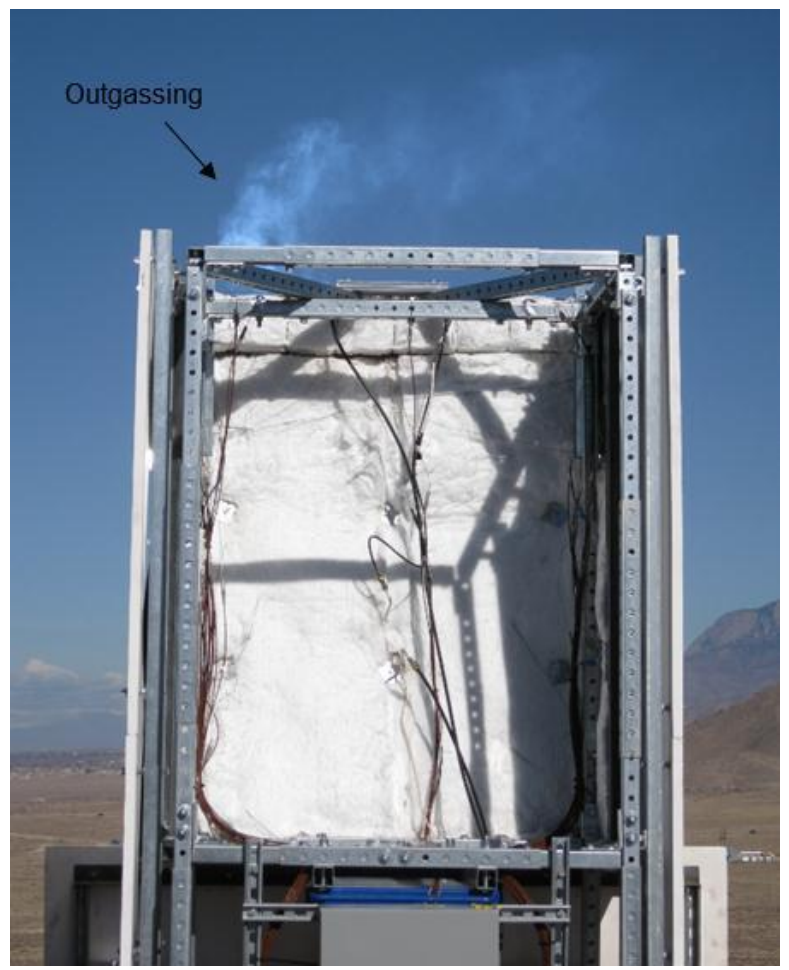

Outgassing During test

\section{Test \#2-50 Suns}

The second testing was again performed at 50 suns. The heliostats were brought on at slightly quicker intervals $(2-3$ minute). The test showed the same results as the initial test. The insulation still smoked / outgassed and the peak temperatures were at the front, metal shield. Again there were no noticeable changes to the structure or insulation after the testing.

\section{Test \#3-100 Suns}

The heliostat target was raised 12 inches for the third test. This was done to more accurately simulate a full receiver with molten salt flowing through the tubes. This in turn lowered the temperatures on the front, metal shield. The test was performed at 100 suns, but with the target raised, the temperatures on the front, metal shield stayed the approximately the same $\left(850-900^{\circ} \mathrm{F}\right)$. The heliostats were brought on at 2 - 3 minute intervals. The insulation continued to smoke / outgas. Again there were no noticeable changes to the structure or insulation after the testing. 


\section{Test \#4-150 Suns}

The test was performed at 150 suns with the heliostats brought on at approximately 1 minute intervals. The target was again 12 inches above the upper flux gage to simulate a full receiver. The front, metal shield temperatures reached $1150^{\circ} \mathrm{F}$. However, this did not cause any noticeable changes to the shield or any other part of the structure. The insulation continued to smoke / outgas. Another test performed was a repeat of the 150 sun test to get a longer steady state temperature profile. Clouds caused a shadow during the first test at 150 suns. The results of the test mirrored the forth test with the front, metal shield temperatures at approximately $1150^{\circ} \mathrm{F}$ and the insulation smoking / outgassing. There were no noticeable changes to the structure or shielding.

\section{Test \#5-200 Suns}

The 200 sun test was performed with the heliostat target raised to 24" above the top heat flux gage. This was done to lower the temperatures the front, metal shield would see. The heliostats were brought on at 30 second intervals. The total number of heliostats on the target was 26 . The insulation seemed to smoke / outgas less during this test. The peak temperatures were still at the front, metal shield but the temperatures were less than $700 \mathrm{~F}$. Again there were no noticeable changes to the structure or insulation after the testing.

\section{Test \#6-250 Suns}

The 250 sun test was brought up to test conditions from 200 suns instead of from 0 . The results were similar to the 200 sun test with the peak temperatures at the front, metal shield $\left(\sim 850^{\circ} \mathrm{F}\right)$, light smoking / outgassing from the insulation, and no noticeable changes to the structure or the insulation.

\section{Test \#7-300 Suns}

The 300 sun test was brought up to test conditions from 250 suns. The target for the majority of the heliostats stayed the same ( 24 inches above the top heat flux gage), but two heliostats were targeted 2 inches lower. This was done to get the correct flux without bringing on too many extra heliostats. The results were similar to the 250 sun test with the peak temperatures at the front, metal shield $\left(\sim 1050^{\circ} \mathrm{F}\right)$, smoking / outgassing from the insulation, and no noticeable changes to the structure or the insulation.

\section{Test \# 8 \& 9-300 Suns with Water Soak}

The next two tests were performed with the high temperature composite board being soaked with water prior to the testing at 300 suns. About 140 ounces were poured. The test started at 0 suns and the heliostats were brought on at approximately 15 second intervals. The target for the majority of the heliostats stayed the same ( 24 inches above the top heat flux gage), but some heliostats were targeted lower to get the correct heat flux. There were more clouds during these tests so additional heliostats had to be brought on to get the correct heat flux. The heliostats also had to be brought on and off during testing to try to keep the heat flux relatively stable. The initial result as the heliostats were brought on was vaporization of the water. Most of the vapor was seen by 100 suns. The insulation still smoked / outgassed during the test. The only change that was noticed after the testing was that the high temperature epoxy used to attach the blocks covering the bolts on the top front shield had started to crack. The top, center, block was repaired with additional high temperature epoxy between the first and second test. The epoxy had some additional cracks after the second test but was still holding the block 
solidly. The peak temperatures were still on the front, metal heat shield $\left(\sim 1100^{\circ} \mathrm{F}\right)$. The inspection after testing showed some small pits in the front shield. These were all nearly imperceptible and were less than .100 inches deep.

\section{Test \#10-350 Suns}

The 350 sun test was performed with the heliostats targeted previous location. There was very little smoke or outgassing during the test. The peak temperatures were again at the front, metal shield $\left(\sim 1000^{\circ} \mathrm{F}\right)$, and the high temperature composite board peak temperature was $\sim 850$ to $900^{\circ} \mathrm{F}$. During the posttest inspection the Top, front, right, side bolts were discolored. They seemed to be of a rust color. The left side was not as noticeably discolored. No other changes were noticed.

\section{Test \#11-400 Suns}

The 400 sun test was performed with the heliostats targeted previous location. There was very little smoke or outgassing during the test. The peak temperatures were again at the front, metal shield $\left(\sim 1000^{\circ} \mathrm{F}\right)$, and the high temperature composite board peak temperature was $\sim 850$ to $900^{\circ} \mathrm{F}$. There was some smoke / outgassing during the test. During the posttest inspection, the side bolts were slightly more rust colored. Additional spots on the side panels around the washers were also discolored. No other changes were noticed.

\section{Test \#12- 450 Suns}

The 450 sun test was performed with the heliostats targeted previous location. There was very little smoke or outgassing during the test. The peak temperatures were again at the front, metal shield $\left(\sim 1200^{\circ} \mathrm{F}\right)$, and the high temperature composite board peak temperature was $\sim 800^{\circ} \mathrm{F}$. There was some smoke / outgassing during the test. During the posttest inspection, the side bolts were more rust colored. The high temperature composite board panel is now bowed. No other changes were noticed.

\section{Test \#13 - 500 Suns}

The objective of this test was to subject the test article to 500 suns as read by flux gauge \#2. Sixty heliostats were used to provide the power and were brought on 20 at a time. The flux was held at or above 500 suns for a little over an hour. The highest temperatures recorded on the test article were a thermocouple (TC) 7 and 8 (front metal panel) which reached an average temperature of approximately $1,270^{\circ} \mathrm{F}$ for the test. The high temperature composite board front panel showed temperatures ranging from 450 to $1,010^{\circ} \mathrm{F}$ depending on location. Outgassing on the right top corner was seen throughout the test.

\section{Test \#14 - 625 Suns}

One extra test was run after all original test matrix tests were completed in an effort to determine the design limits of the test article. The test targeted a flux of 625 suns. Temperatures were carefully monitored as the flux reached the set target and was held for 1 hour. Major outgassing was noticed emanating from the same areas as previous testing. The temperatures throughout the structure reached a relatively steady state condition and the highest average temperatures were seen on $\mathrm{TC} 7\left(1,375^{\circ} \mathrm{F}\right)$ and TC8 $\left(1,285^{\circ} \mathrm{F}\right)$. After testing was complete, inspections showed a major increase of charring around the side bolts as well as the onset of discoloration on the front sheet metal panel. The adhesive that bonded 
Pratt \& Whitney Rocketdyne, Inc.

the caps to the front panel had shown major cracking that was noticed after prior tests, but seemed more prominent after this run. The panel appeared to have little or no change from the previous test.

prome

\section{2_Test \#14 - 625 Suns.tdms}

* T1A 120712 Test \#14 - । B- T5C 120712 Test \#14 - । - P T21 120712 Test \#14 - $\epsilon$-d- T35 120712 Test \#14 - $\epsilon$

$\triangle$ T1B 120712_Test \#14 - $-G$ T6A 120712_Test \#14 - $-Q$ - T22 120712_Test \#14 - $\epsilon$ - - T36 120712_Test \#14 - $\epsilon$

— T1C 120712 Test \#14 - I - D T6B 120712 Test \#14 - I - R T23 120712 Test \#14 - $\epsilon$ - f T37 120712 Test \#14 - $\epsilon$

$\rightarrow$ T2A 120712_Test \#14 - I E- T6C 120712_Test \#14 - I - S T24 120712_Test \#14 - $\epsilon$ - $g$ - T38 120712_Test \#14 - $\epsilon$

$\varangle$ T2B 120712 Test \#14 - I F- T7 120712 Test \#14 - 6 $c$ - T T25 120712 Test \#14 - $\epsilon$ - h- T39 120712 Test \#14 - $t$

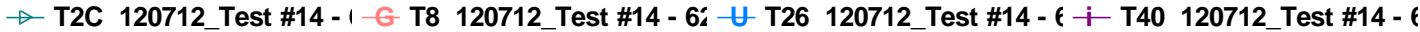

$\diamond$ T3A 120712_Test \#14 - - - - H T9 120712_Test \#14 - $6 \dot{c}-\vee$ T27 120712_Test \#14 - $\epsilon$ - - T43 120712_Test \#14 - $\epsilon$

$\square$ T3B 120712 Test \#14 - $\mid$ - T T10 120712 Test \#14 - $\epsilon-W$ T28 120712 Test \#14 - $\epsilon-k-$ T44 120712 Test \#14 - $\epsilon$

—- T3C 120712_Test \#14 - $\mid$ - T11 120712_Test \#14 - $\epsilon-x$ T29 120712_Test \#14 - $\epsilon$ + T45 120712_Test \#14 - $\epsilon$

$\neg$ T4A 120712_Test \#14 - $\mid$ - K T12 120712_Test \#14 - $\epsilon$ - T30 120712_Test \#14 - $\epsilon$ - m T46 120712_Test \#14 - $\epsilon$

$\triangle$ T4B 120712_Test \#14 - - - L T15 120712_Test \#14 - $\epsilon$ Z T31 120712_Test \#14 - $\epsilon$ - $n$ - T47 120712 Test \#14 - $\epsilon$

T4C 120712_Test \#14 - - - M T16 120712_Test \#14 - $\epsilon$ - a- T32 120712_Test \#14 - $\epsilon$ - - - T48 120712_Test \#14 - $\epsilon$

$\triangle$ T5A 120712 Test \#14 - I - N T17 120712 Test \#14 - $\epsilon$-b- T33 120712 Test \#14 - $\epsilon$ - p- T49 120712 Test \#14 - $\epsilon$

A T5B 120712_Test \#14 - $-\odot$ - T18 120712_Test \#14 - $\epsilon$ - - T34 120712_Test \#14 - $\epsilon$-q T50 120712_Test \#14 - $\epsilon$

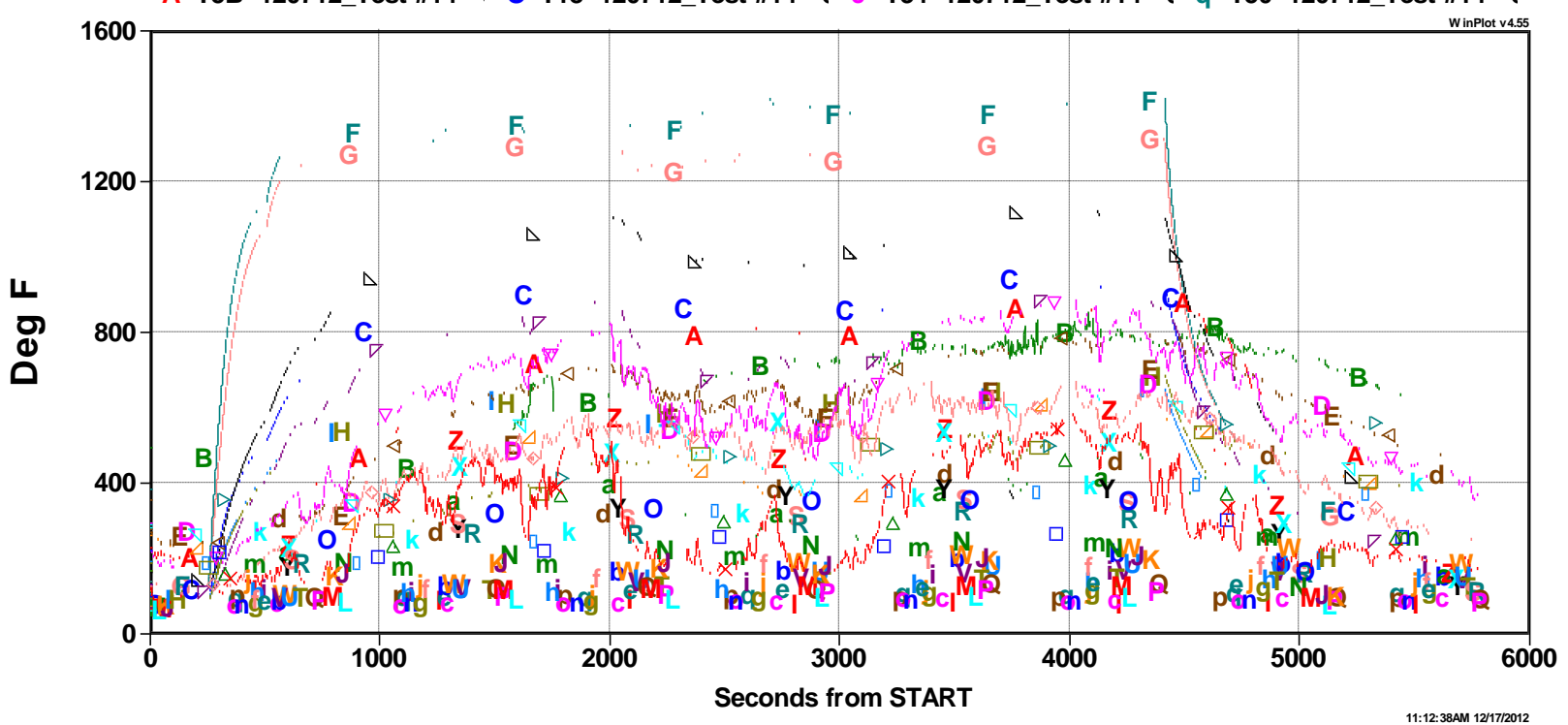

Typical Test Data, TC Recordings at 625 Suns

\section{Summary of Heat Shield Tests:}

Overall the test fixture and shielding performed well. The front shields receive the highest amount of solar flux (solar spillage). The front sheet metal shield worked well in protecting the internal support structure. Temperatures recorded on the front sheet metal shield never exceeded $1,500^{\circ} \mathrm{F}$. The high temperature composite board heat shields cut the internal structural temperatures down to very manageable temperatures. The internal temperatures never were above $425^{\circ} \mathrm{F}$ and most of the temperatures were below $300^{\circ} \mathrm{F}$. The temperatures decreased quickly from the outer thermocouples to the interior thermocouples. There are also both sheet metal and high temperature composite board side shields. Even though these side shields receive less solar spillage they also worked well during testing.

The sheet metal shields held up very well during the testing. The peak temperatures were approximately $1,435^{\circ} \mathrm{F}$. The sheet metal only showed slight warpage between attachment bolts. Maximum operation temperature of 300 series sheet material is $1,700^{\circ} \mathrm{F}$ so the temperatures during the testing did not exceed the maximum operating temperatures of the material. The overall front sheet metal shield darkened 
slightly in some local areas near the bolts at the top of the sheet metal shield. This is the area where the highest temperatures were recorded. This may be because to the $90^{\circ}$ bend at the top area of the sheet metal causes a slight magnification of the solar flux. The paint seemed to be adhered well to the metal, but future testing should be done with the paint applied in a uniform fashion to get the best performance. A more uniform painting of the shield would produce even better results and would lower temperatures on the metal. The risk of too much paint is that the paint would crack and peal during operations. All the sheet metal screws functioned well following the testing.

\section{Insulation Front Shield}

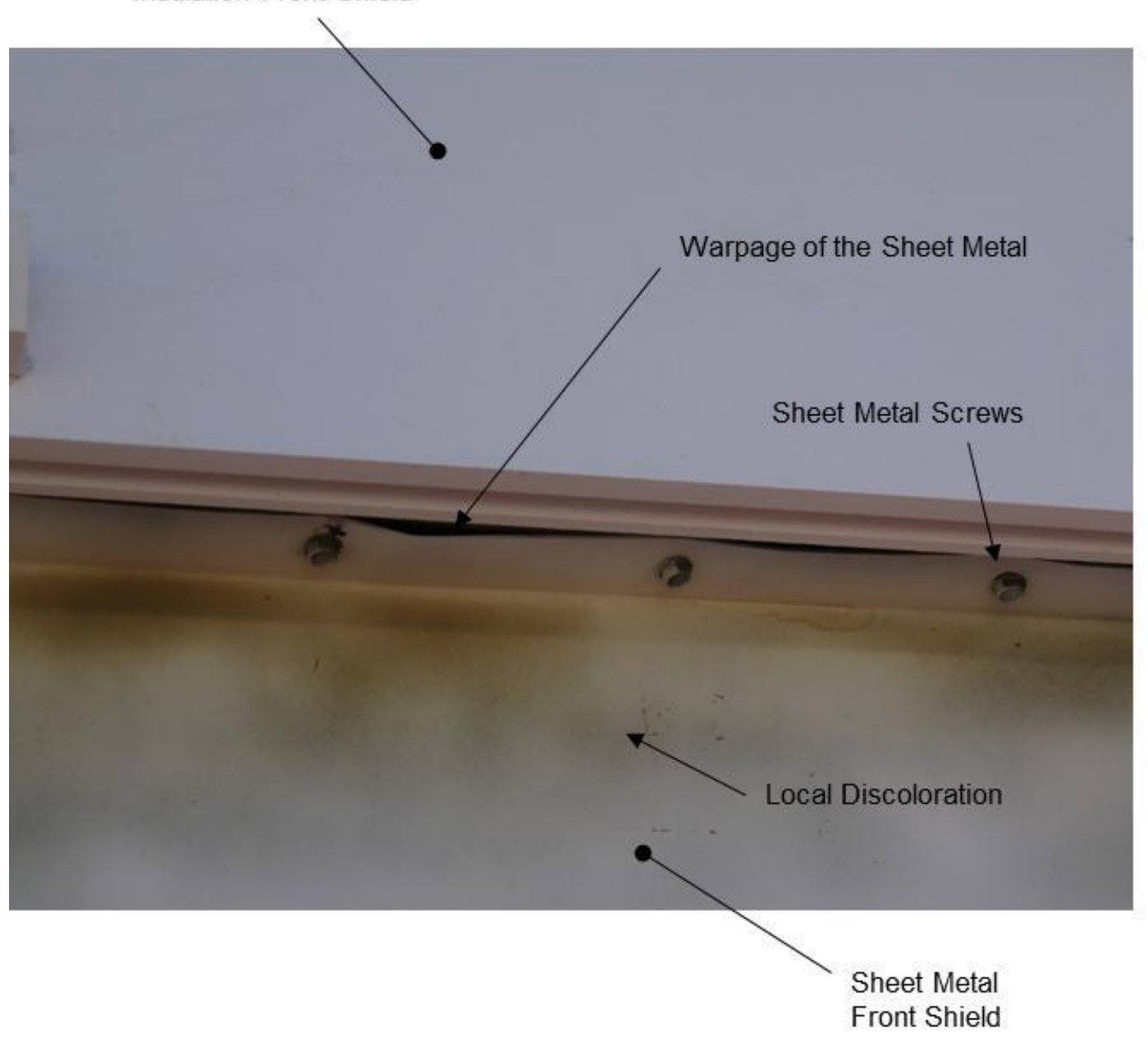

Front Shield, Post Heat Shield Testing 
The fastener covers located on the side panels of shielding were left off intentionally to test the effects of solar flux on unprotected stainless steel fasteners. Some surface discoloration was observed. The fastener function normally and no damage was noted.

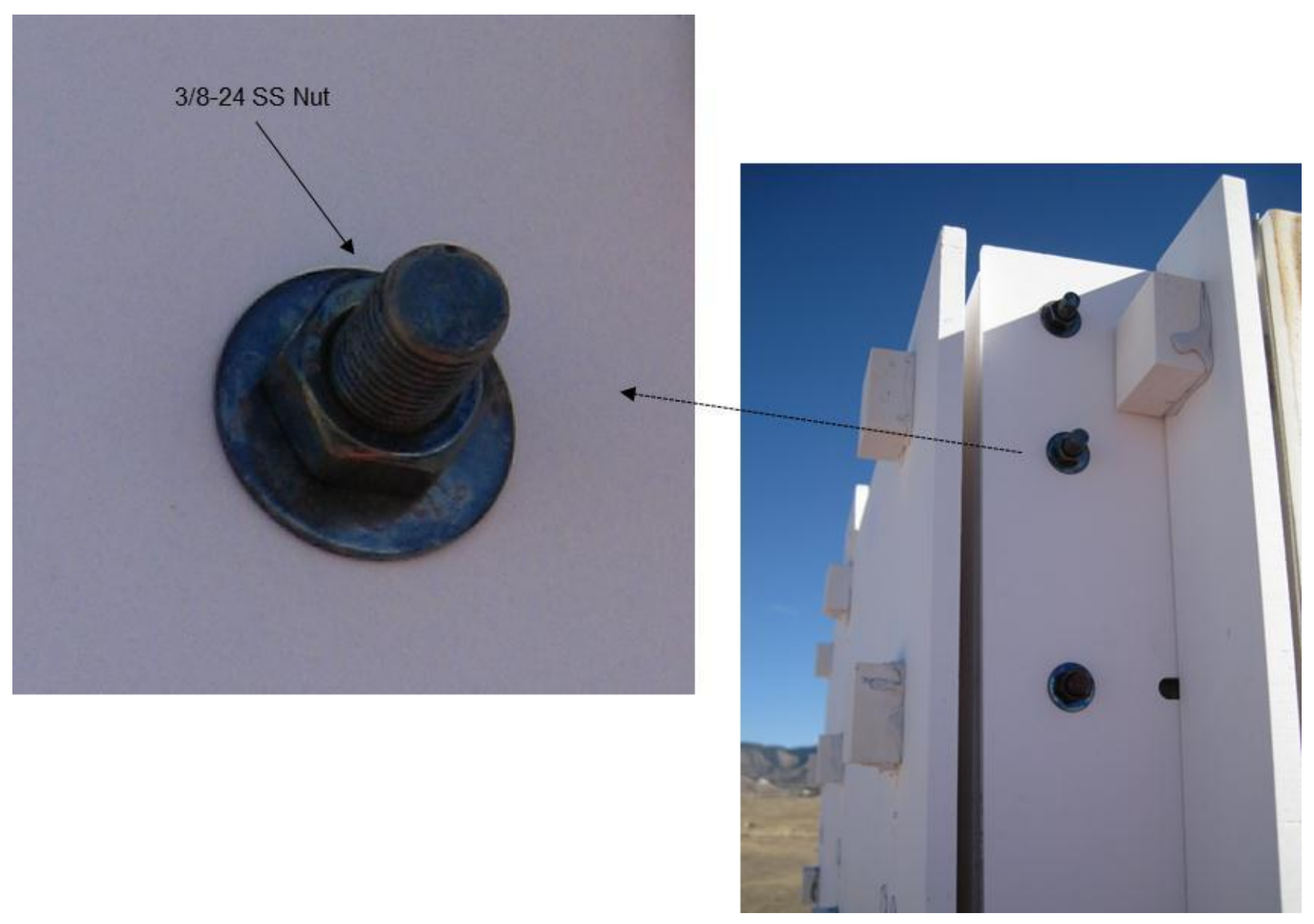

Unprotected Fastener, Post Heat Shield Testing

The purpose of the high temperature composite board shields is to protect the internal support structure from the high temperatures created by the solar spillage. The double layer panels on the front face of the heat shields drastically reduced the temperatures, created by the solar spillage, before reaching the internal support structure. A 625 nickel alloy material was used on the support structures of the heat shields because the temperatures reaching these components were expected to be much higher. Since the test is simulating an actual receiver with molten salt flowing through the tubes, the focus of the heliostats is approximately 20 " above the top of the test assembly. Therefore the highest solar flux is at the top of the test assembly. One of the two flux gauges is located at the top of the test assembly. Thermocouples ("C") are attached to the support structure behind the front double layer panels. The highest temperature recorded in this area is $611^{\circ} \mathrm{F}$. The conclusion is that either the double layer panels would work well in an advanced receiver where much higher temperatures are required or that the alloy support structure could be replaced with a lower cost commercial grade stainless steel. 
Covers were applied over the fasteners that are securing the panels to the structure. A high temperature $\left(2,500^{\circ} \mathrm{F}\right)$ epoxy that has a low expansion rate attached the covers to the front panels. The high temperature epoxy held up well, but a more controlled process of mixing, applying, and curing should be used for longer term applications. The epoxy hardened quickly and did not allow the blocks to fall off, but the epoxy did seem to be susceptible to cracking when it absorbed water. This might be able to be reduced with a longer and more controlled curing process. Also, the epoxy might be able to replace the blocks if the bolts are sunk into the panel and can just be covered with the epoxy. The bolts that held the flux gage to the structure were covered in this fashion and there was no noticeable cracking or damage to the epoxy. In addition forming a fillet with the epoxy residue at the interface of the cover and the panel would add additional strength to cover. Following testing the covers were removed. A hammer was required. Some covers needed a good strike from the hammer while others required a slight tap of the hammer. The covers did well in protecting the fasteners located under to cover. Some surface discoloration was observed but the fastener functioned normally and no damage was noted.

\section{Front Insulation Panel}

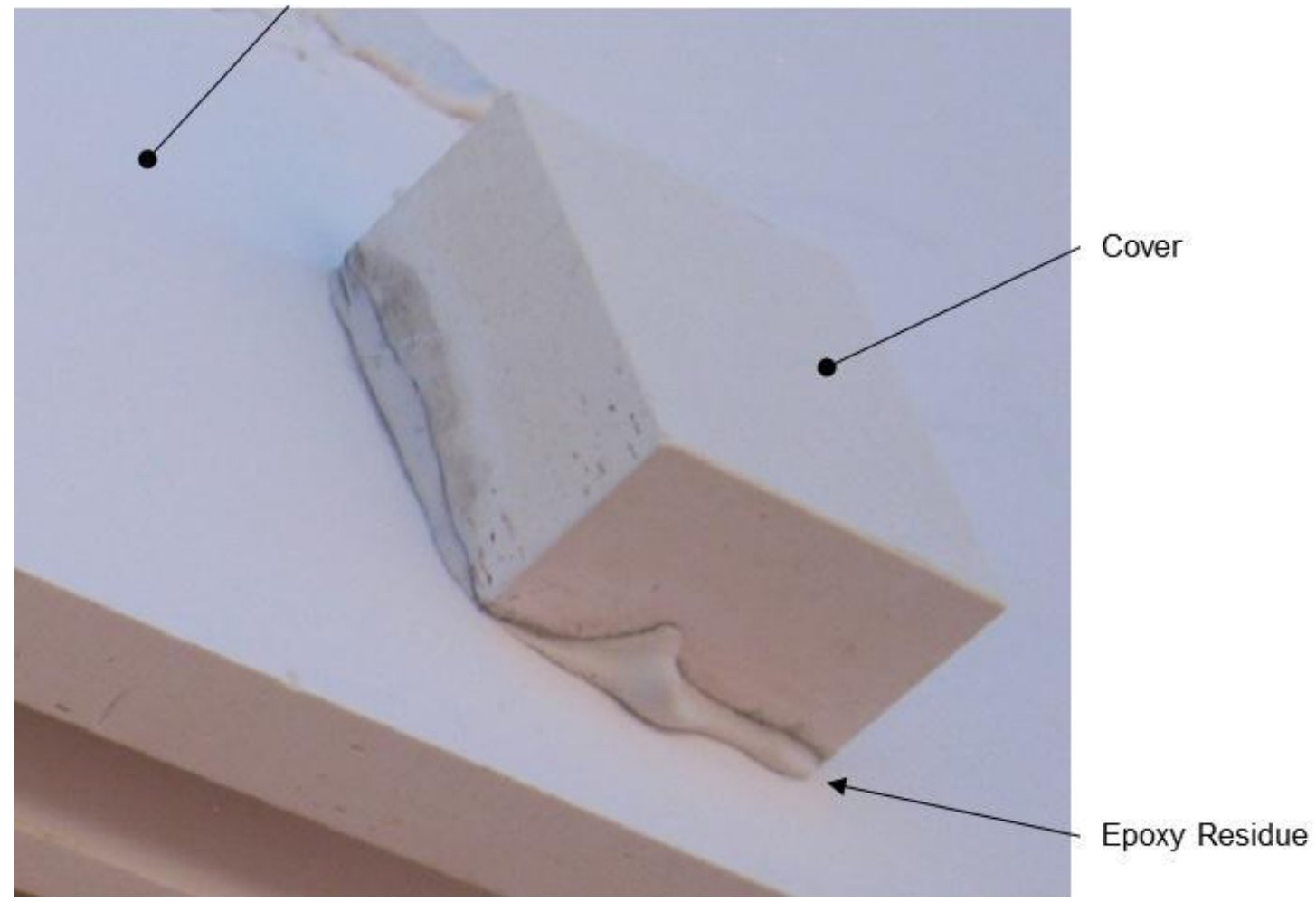

\section{Fastener Covers}

\subsubsection{TUBE WELD EXPOSURE TEST}

The purpose of the tube weld exposure test is to expose a welded tube to the solar flux and determine if the integrity of the weld is maintained. Two tubes sections of the same material type are welded together using a standard manual GTAW weld process. The amount of weld drop through on the inside diameter 
of the weld is minimal. The weld drop through would have an insignificant impact on molten salt flowing through the tubes in a full receiver during operation.

\section{Tube Test \#1 - Instrumentation Checkout / Weld Stress Test}

One objective of Tube Test \#1 is to expose two tubes of different material types with circumferential welds to elevated temperatures. These tubes were placed in the tube holder on top of the high temperature composite board panel. One thermocouple was installed near the weld on each tube on the side closest to the heliostat array. The other test objective was to ensure that the newly installed instrumentation was working properly.

Once the instrumentation checked out the test team proceed with the rest of the test. The target temperature for the tubes is $1,050^{\circ} \mathrm{F}$. It was a challenge to hold a steady temperature due to the changing cloud cover but by continually monitoring the temperature and heat flux of the test article, heliostats were added or removed to compensate. It was noticed that in order to reach the targeted temperature, about 40 suns were required. The test objective was achieved as the tubes were subjected to the elevated temperature for 30 minutes. The average temperature read at the tube welds during this time was $1,150^{\circ} \mathrm{F}$ (T19) and $1,110^{\circ} \mathrm{F}(\mathrm{T} 20)$ while the peak temperature was $1,339^{\circ} \mathrm{F}$.

After the first test, the test assembly was rolled back from the edge of the tower and the tubes were inspected. The tubes showed some slight discoloration on the exposed surfaces but otherwise no damage or deformation. No visual cracking at the weld.

\section{Tube Test \#3 - Weld Stress}

In order for the tube welds to accumulate more thermal cycles, Tube Test \#3 was a repeat of Tube Test \#1. During this test, a maximum of 30 heliostats were needed in order to maintain 1,050 degrees F. After the 30 minute exposure, the only change observed was that the back-side of the tubes (away from heliostat field) showed slightly different colors relative to each other. The one tube showed a darker yellow-ish tint while the other was a little lighter in color. Otherwise, no noticeable changes to the discoloration on the front-side of the tubes or weld anomalies were noted.

\section{Tube Test \#4 - Weld Stress Test}

This was another repeat of the weld stress test at 1,050F. Unfortunately, due to some large clouds moving in, the test was aborted since the temperature could not be attained. The tubes, however, were exposed to a thermal cycle up to 1,200 degrees $\mathrm{F}$ before test termination.

With the clouds still present it was decided to increase the number of heliostats in an attempt to achieve the desired 1,050 degrees F. Twenty heliostats were brought on at once before an additional 25 at smaller increments. The test was successful and the tubes were exposed to 30 minutes of elevated temperatures. The peak temperature got up to $1,385 \mathrm{~F}$ but the average temperature as read by the tube thermocouples was approximately $1,160 \mathrm{~F}$. Post-test inspections of the tubes showed no change since last test.

\section{Tube Test \#6 - Weld Stress Test}


Tube Test \#6 was the final weld stress test. Twenty heliostats were brought on at once and from there, several were added and removed in an attempt to hold a steady temperature. The maximum peak temperature reached $1,350 \mathrm{~F}$ but the average temperature over the duration of the test was around $1,110 \mathrm{~F}$. After 30 minutes of elevated temperatures, the tubes showed no visible change from the previous test.

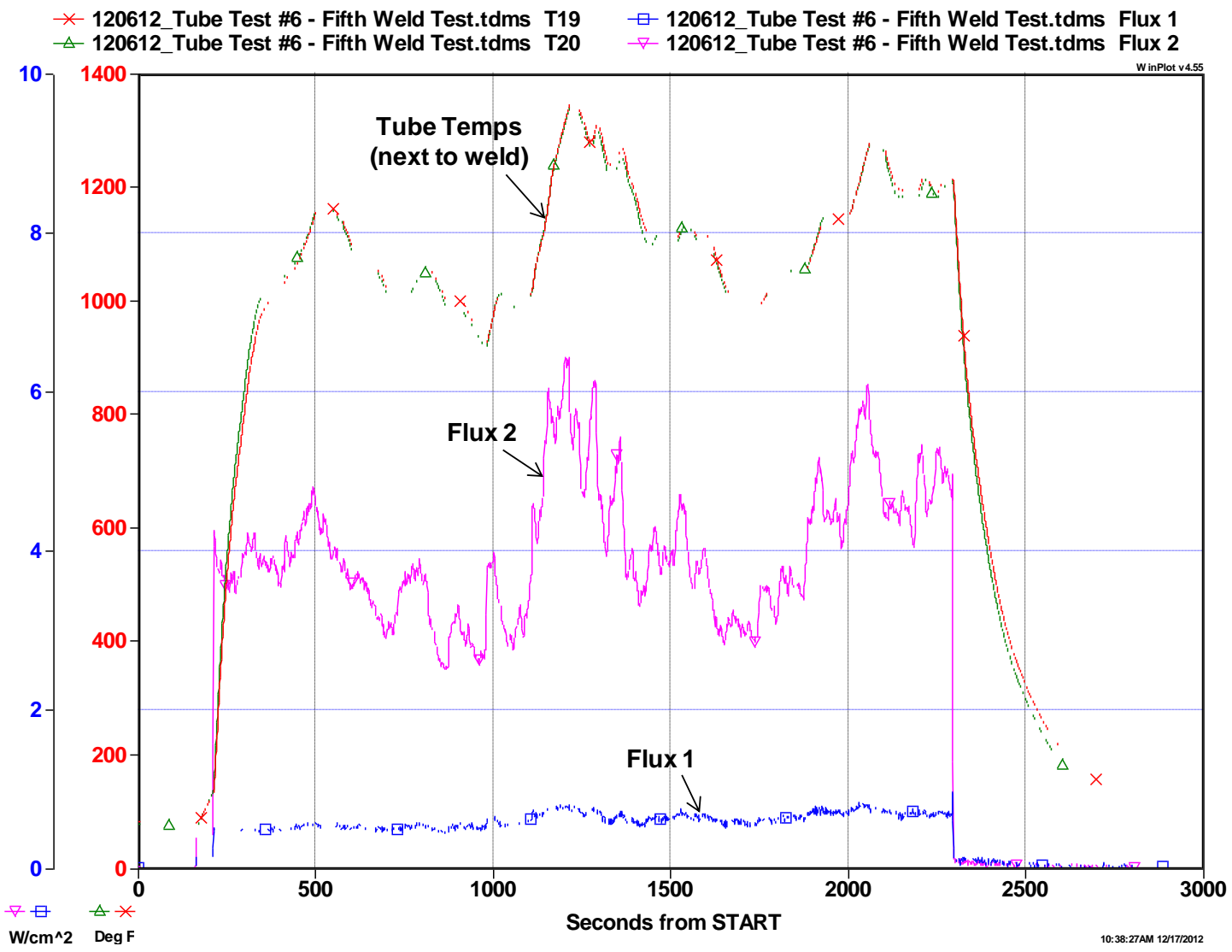

Typical Tube Weld Test Data 

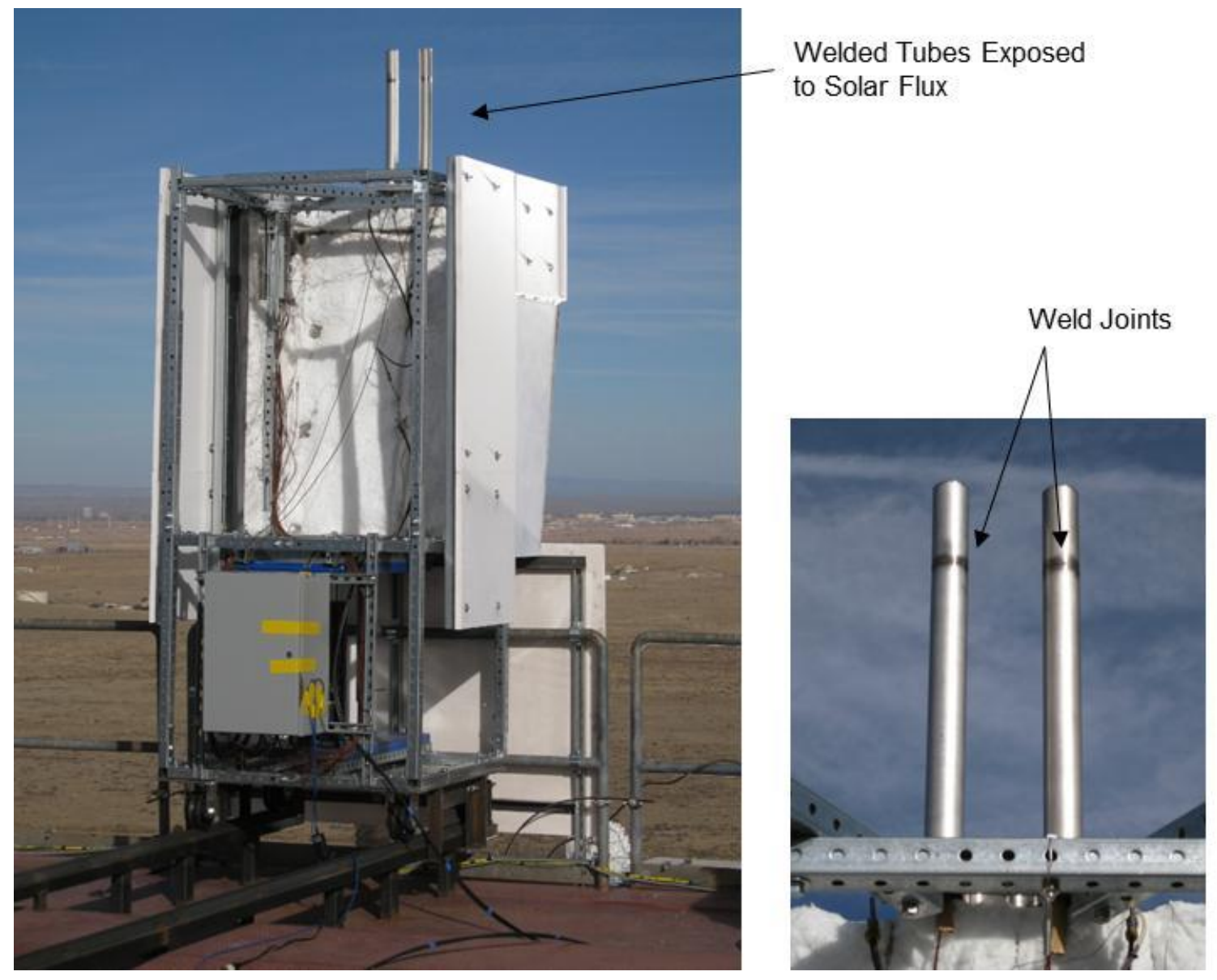

Actual Tube Weld Test

Tube weld exposure test completed with no anomalies noted in the welds. Visual inspection shows no damage to the surface of the weld.

\subsubsection{TUBE PYROMARK PAINT CURE TEST}

The purpose of the Pyromark paint test is to demonstrate that the paint can be cured using heliostats (note: this is listed as tube test 2 in the test matrix). A commercial CSP receiver paints the receiver tubes with a black heat absorbing paint. Typically this is Pyromark 2500 Flat Black Paint. The paint increases the efficiency of the receiver to absorb heat energy from the heliostats. During initial fabrication the tube sections go through a complex cure process using a furnace. However if a tube paint is damaged during assembly it would be impossible to cure a painted receiver tube in a furnace. This test uses heliostats to cure the paint. 


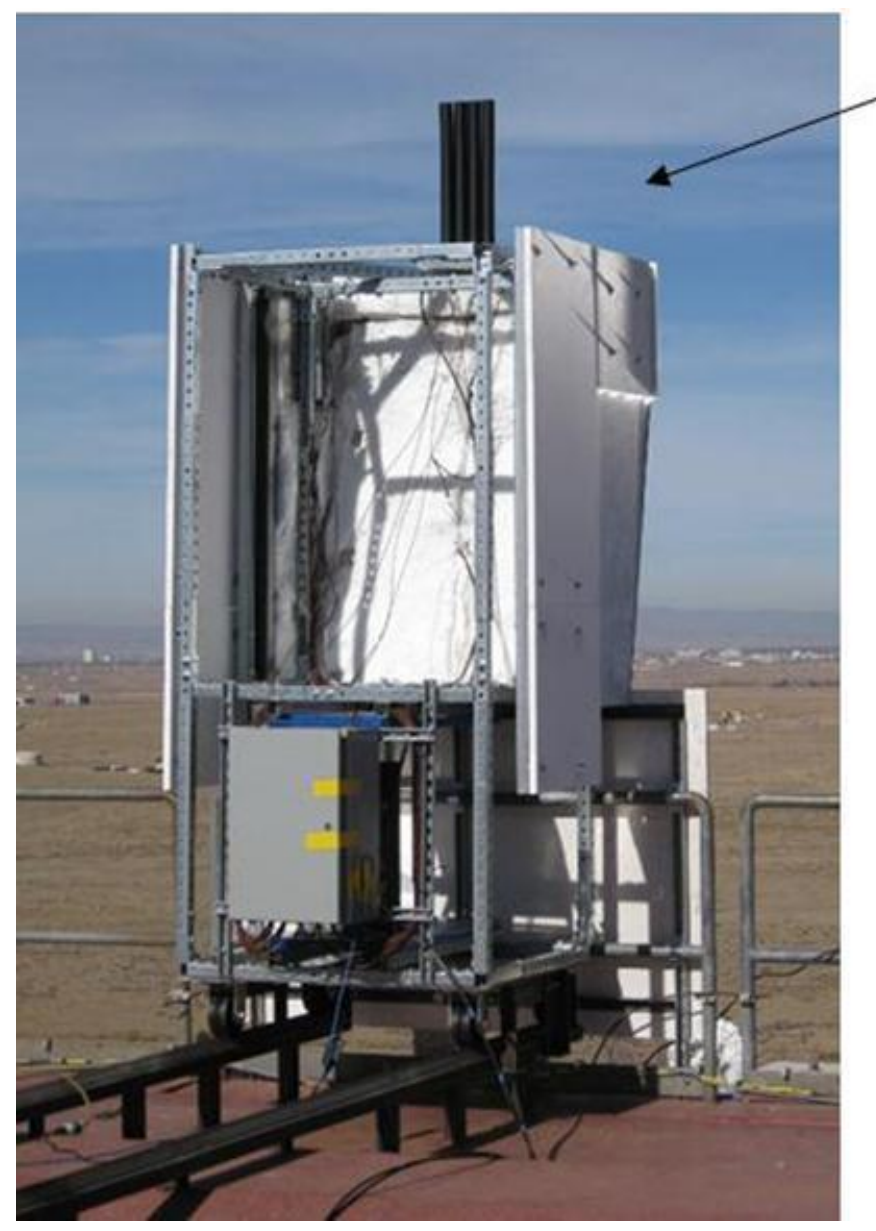

\section{Painted Tubes}

Exposed to

Solar Flux

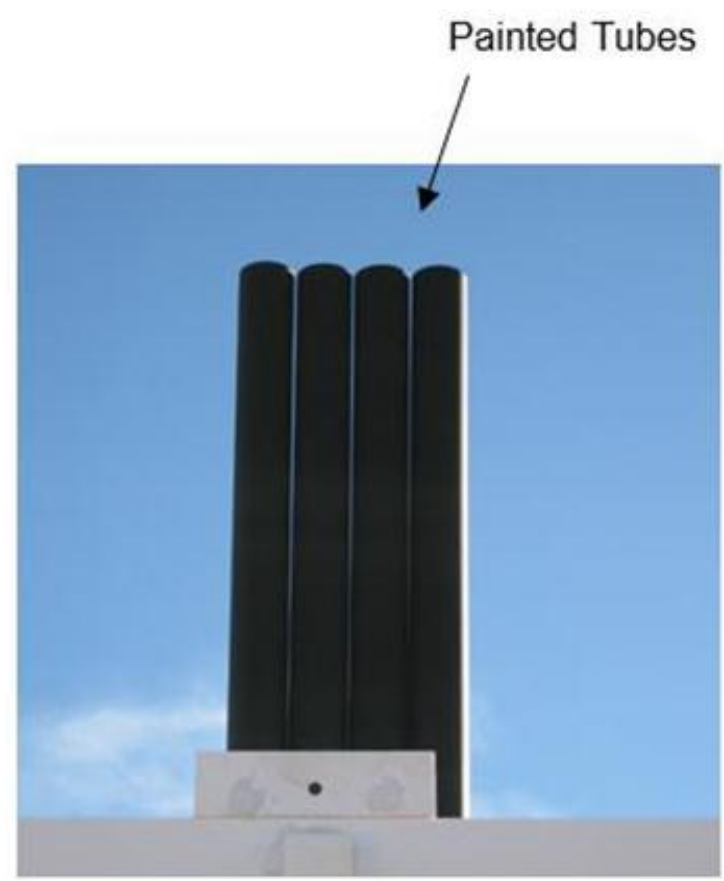

Actual Paint Curing Test

\section{Tube Test \#2 - Paint Cure}

The objective of this test was to see how well Pyromark paint applied to receiver tubes will cure on top of the solar tower. Four 2" diameter tubes were spray painted and installed into the tube holder on top of the test rig. Thermocouples were tack welded to the inside of each tube and located on the side closest to the heliostat array. 
The targeted test profile ramped the tube temperature from 250 to $1100^{\circ} \mathrm{F}$. For the first step in temperature, one heliostat was enough to provide the required heat flux to achieve $250^{\circ} \mathrm{F}$ nominal temperature. That same heliostat was also used for the second temperature cure at $480^{\circ} \mathrm{F}$. In order to provide enough heat for the third set temperature, seven heliostats were used. Some outgassing was noticed emanating from the top of the tubes when passing approximately $600^{\circ} \mathrm{F}$ but soon stopped. Due to the difficulty in accurately subjecting the tubes to a steady temperature over a long period of time, the decision was made to combine the third and fourth temperatures into one long two hour hold targeting 1,000 to $1,100^{\circ} \mathrm{F}$. Again, outgassing was noticed at about $1,000^{\circ} \mathrm{F}$. Tube temperatures and associated flux readings for the entire run is plotted below.

Post-test visual inspections showed that the paint had gone from a shiny black to a duller finish, flat black which would indicate successful curing. A simple fingernail scratch test of the cured paint showed the paint did not flake off and was firmly adhered to both tube materials. This demonstrates that a local area of the receiver tubes can have the paint repaired on the tower and cured using heliostats.

\subsubsection{STRUCTURAL ASSESSMENT}

The Heat Shield Test Assembly was tested at the NSTTF at Sandia National Laboratories. The heat shield was exposed to a maximum of 500 suns over a 13 test series and a 625 sun test was added to the end of the test series to demonstrate capability above the design heat flux. Thermocouples were attached to multiple locations on the heat shield and the steel uni-strut support structure.

The recorded temperatures during the testing were largely a function of the location of the aim point of the heliostats. For the majority of the heat shield testing, the heliostats were targeted at approximately 2 feet above the top heat flux gage location which was at the top of the heat shield. This allowed the solar spillage from a receiver panel to be simulated on the heat shield.

The peak recorded temperature on the heat shield was approximately $1300^{\circ} \mathrm{F}$ during the 450 and 500 sun tests and $1430^{\circ} \mathrm{F}$ during the 625 sun test. This occurred at the top thermocouple locations on the front metal heat shield. Observed temperatures on the lower part of the front metal heat shield were significantly lower. The exposed surface of the metal heat shield was painted with a coat of white VHT paint. The metal heat shield was fabricated from 304L stainless steel sheet metal which can tolerate temperatures in the range of $1700^{\circ} \mathrm{F}$.

During the initial low heat flux testing, no significant change to the metal heat shield was noted. During the higher heat flux tests, some warping of the front shield sheet metal was noted between the fasteners along the top and side edges of the shield. The fasteners act as a constraint against the thermal expansion of the shield and stainless steel has a relatively high coefficient of thermal expansion of approximately 10 $\mu \mathrm{in} / \mathrm{in} / \mathrm{F}$ at $1200^{\circ} \mathrm{F}$. During the final 625 sun heat shield test, discoloration of the upper part of the front metal heat shield was noted.

The stainless steel fasteners holding the front high temperature composite board shields in place were protected by caps during testing. During inspection after testing, some of caps were removed. These fasteners did not show any visible indication of degradation. The fasteners on the side panels would also typically have a cap to protect the exposed fastener, but for this test series were not protected with caps. These fasteners began to visibly darken, an indication of oxidation, beginning with the 400 sun and higher 
heat flux tests. The exposed fasteners on the side board panels showed only minor indication of discoloration at the higher heat flux tests.

The high temperature composite board panels themselves are only supported at the locations of the fasteners holding them in place and, therefore, must maintain their structurally capability to resist wind loading. During the testing, the panels did not show any significant visible signs of degradation. The test series included two tests in which the panels were soaked with water immediately before a 300 sun heat flux was applied.

Thermocouples on the uni-strut support structure were located near the top and bottom levels of the heat shield. Observed temperatures at these locations remained below $110^{\circ} \mathrm{F}$ which is below the typical $400^{\circ} \mathrm{F}$ temperature service limit for plain steel.

Inspection of the test stand support structure, heat shield support structure and the heat shield panels at the conclusion of the test series indicated that the test article performed as expected and there was no indication of any significant structural concern. Further evaluation would be needed to determine any potential long term effect to exposed fasteners on the heat shield or to exposure of the overall heat shield to the higher 625 sun heat flux over an extended period of time.

\subsubsection{AEROTHERMAL ASSESSMENT}

The thermal analysis which was completed for the CSP DOE receiver design review (June 29, 2010) showed significantly higher outer layer temperatures. The predicted maximum temperature for the primary shield outer layer high temperature composite board was $1329^{\circ} \mathrm{F}$. The test data shows the primary shield outer layer maximum temperature to be $1100^{\circ} \mathrm{F}$. The difference mostly likely is due to the conservative approach which is incorporated into the analysis process. One key contributor in the difference may have been the application of natural convection instead of forced convection on all external surfaces for the analysis. During testing, there was always a slight breeze which would aid in reducing the temperatures. Another factor which could have contributed in the discrepancy is the use of constant material properties in the thermal analysis. Due to the lack of available material properties, it was an assumption which was necessary.

Overall the heat shield testing was a success. Valuable material and design data was obtained. The double Zircar heat shield design endured all tests as well as proved that a double high temperature composite board design can significantly reduce the base support structure temperatures to ranges which allow the use of less exotic, less costly materials. Although the use of an exotic, costly material may be necessary for the outer layer, the overall cost may be reduced.

\subsubsection{PRODUCTION SCENARIO}

The innovative receiver design ideas developed through this project will be ready to be implemented into future CSP plant designs. Fabrication and testing key components of the receiver demonstrate that the design is both economically and functionally feasible. The results of the testing allowed our analysis to be anchored to actual CSP operating conditions. The key components includes (3) different heat shields designs, clip support assembly, a one piece tube clip. The test for the clip support assembly and the one piece clip was to demonstrate that they could be fabricated. Even though scaling these designs up to a full size CSP plant would be require some design effort, it could be done will little impact to cost of schedule. 
While the cost of one-off fabrication of the development hardware is relatively high, scales of economy would drastically reduce the cost of mass produced hardware. Depending on the quantity of parts ordered the cost could be reduced $80 \%$ by distributing non-reoccurring costs over a larger part quantity.

Two tube repair process have been developed and tested. A weld repair method for repairing small pins holes in receiver tubes and a process for repairing damaged Pyromark painted surfaces. Both processes could be applied to current CSP plants in operation with little development effort.

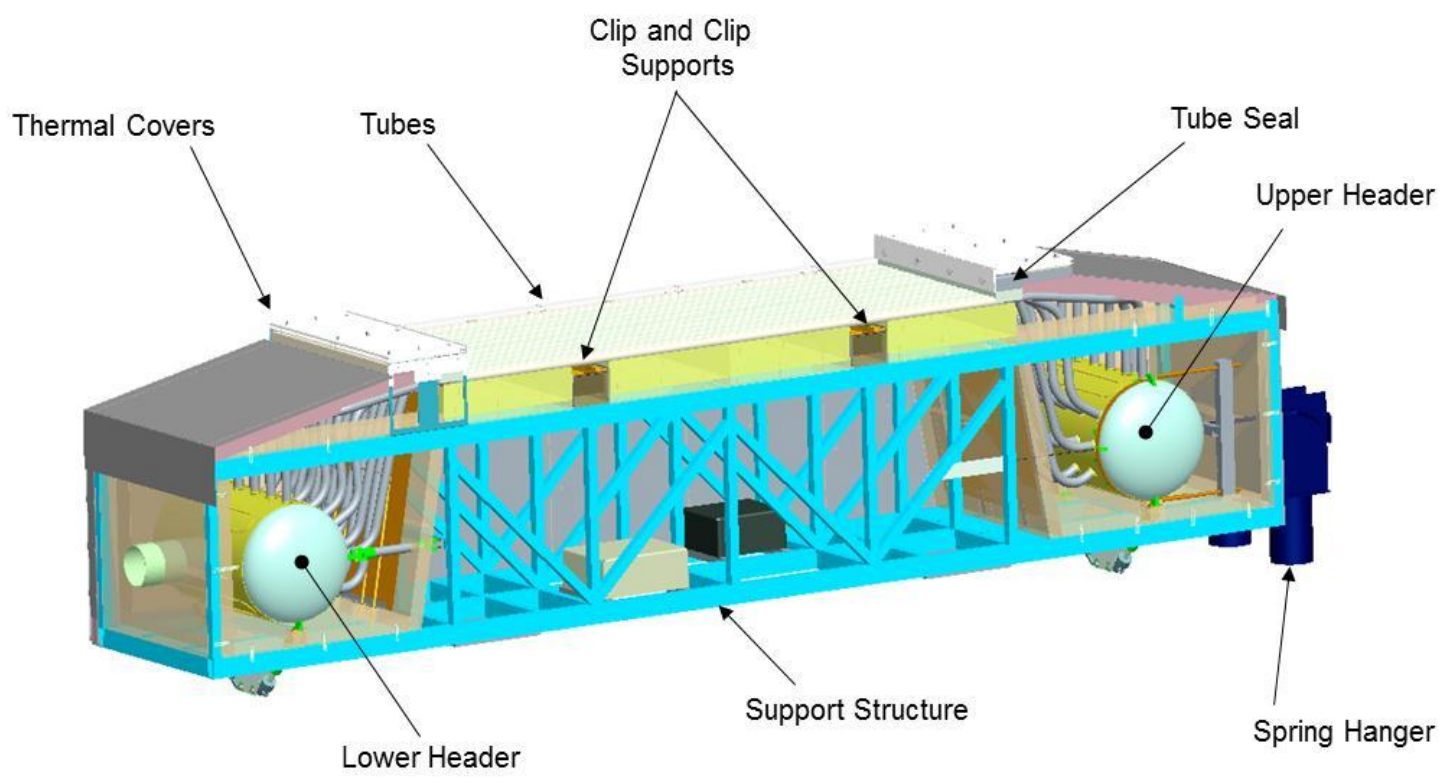

Receiver Design

\subsubsection{COST COMPARISON TO FULL SCALE PANEL \& PATH FORWARD}

The innovative designs implemented on this project will reduce the cost of a CSP power plant by $\$ 6$ million. This reduction is based on implementing the design changes of this project into a full size CSP plant. The full size power plant takes 14 receivers and since the size of this development receiver and the full scale one are significantly different some assumptions had to be made to equate the values. The subscale receiver was calculated by comparing the cost of a CSP receiver's key components. As an example; the DOE receiver header is $1 / 3$ the size of the Baseline receiver header. Multiplying the cost of the DOE receivers by 3 equalizes the comparison of the 2 header configurations. Then calculating the difference shows the cost savings for the receiver headers. Multiplying the header cost savings by 14 shows the total header savings if the DOE receiver header configuration were to be integrated into a power plant. The $\$ 6$ million cost reduction is based on the sum of the 5 key component cost savings.

A brief explanation of the cost difference achieved in this project is given below to better understand how these values were derived. The header cost improvement is achieved by potentially using welded in stubouts instead of pulled stubouts, in addition to selection of a different vendor that is more cost 
effective. The lower tube cost is achieved by using lower cost material, which is roughly one third cheaper previously used material. The clip assembly cost reduction is a result of significantly reducing the amount of parts and simplifying the design which makes it easier to manufacture. The much lower cost of the heat shield is gained by: 1) using less expensive SS instead of nickel alloy for the heat shield and support structure, 2) using cheaper heat shield materials, 3) not covering the entire sun exposed area with high temperature composite board as a less conservative analysis approach was taken, 4) creating an easier design to manufacture with less parts, and 5) generating a design that is easier to assemble requiring very little tooling or heavy machinery. Lastly, the thermal insulation is slightly less expensive because of the more modular and easier to assemble than the highly customized design of the full size plant.

A plan has been developed and implemented to practice repairing and replacing damaged tube sections while the receiver is not in operation. This will reduce the amount of down time for unscheduled maintenance on full size plants and will result in an increase in plant availability of $0.1 \%$, with a value of approximately $\$ 3 / \mathrm{kW}$-hr. This is an engineering estimate based on the ability to perform the tube repair and replacement operation discussed in Section 3.2.1.7. The in place tube repair will allow repairs to be made over one night eliminating a three day shutdown that would be required for a full tube replacement. We anticipate a tube repair will only be required once every ten years and the cost of each day of lost production is valued at $\$ 1$ million.

\begin{tabular}{|c|c|c|c|}
\hline \multicolumn{4}{|c|}{ COMPONENT COST COMPARISON } \\
\hline $\begin{array}{l}\text { DOE RECEIVER } \\
\text { EXTRAPOLATION }\end{array}$ & BASELINE PANEL & DIFFERENCE & $\begin{array}{l}\text { FULL PLANT } \\
\text { (14 PANELS) }\end{array}$ \\
\hline \multicolumn{4}{|c|}{ HEADER } \\
\hline$\$ 165,510.00$ & $\$ 208,024.00$ & $\$ 42,514.00$ & $\$ 595,196.00$ \\
\hline \multicolumn{4}{|c|}{ TUBES } \\
\hline$\$ 1,569,626.10$ & $\$ 2,406,009.90$ & $\$ 836,383.80$ & $\$ 836,383.80$ \\
\hline \multicolumn{4}{|c|}{ CLIP ASSEMBLY } \\
\hline$\$ 41,389.00$ & $\$ 88,265.00$ & $\$ 46,876.00$ & $\$ 656,264.00$ \\
\hline \multicolumn{4}{|c|}{ HEAT SHIELD } \\
\hline$\$ 118,838.61$ & $\$ 385,050.00$ & $\$ 266,211.39$ & $\$ 3,726,959.46$ \\
\hline \multicolumn{4}{|c|}{ THERMAL INSULATION } \\
\hline$\$ 111,484.88$ & $\$ 128,533.00$ & $\$ 17,048.12$ & $\$ 238,673.68$ \\
\hline
\end{tabular}

\begin{tabular}{|c|c|c|}
\hline \multicolumn{3}{|c|}{ FIXED O\&M COST } \\
\hline $\begin{array}{c}\text { DOE RECEIVER } \\
\text { EXTRAPOLATION }\end{array}$ & BASELINE PANEL & DIFFERENCE \\
\hline$\$ 77$ per kW-yr & $\$ 80$ per kW-yr & $\$ 3$ per kW-yr \\
\hline
\end{tabular}

Component Comparison 


\subsubsection{LEVELIZED COST OF ENERGY (LCOE)}

The levelized cost of energy is reduced by the technical improvements performed on this project. The details of the cost savings breakdown are discussed in Section 3.2.6.1. The Roadmap shows that the cost reductions that can be achieved in all components of a CSP plant will be beneficial to the long range competiveness of solar power towers. Since the receiver component is a vital link in the molten salt loop, reductions in both fixed and variable costs will positively reduce the LCOE. The fixed O\&M costs are based on the design changes mentioned in this report and the variable costs are based on the tube repair \& replacement changes that will amount to a reduction of $\$ 3 / \mathrm{kW}-\mathrm{hr}$. Based on the cost differences discussed in Section 3.2.6.1 between this receiver design and the baseline receiver design and the resulting LCOE reduction due to these design changes is $0.21 \phi / \mathrm{kWh}$ nominal, $0.17 \phi / \mathrm{kWh}$ real.

\section{PROJECT SUMMARY}

There are a number of CSP benefits developed by this project. The testing under actual solar condition validated that the designs are feasible. The manufacturing of key components demonstrates that the designs are economically producible. To illustrate this, the levelized cost of energy emphasizes that a focus on continued product innovation will lead to a cost reduction of the price of energy per $\mathrm{kWh}$. This combined with the cost reductions from the increase in the economy of scale and volume production increases, translate into rationale for wanting to prove the innovative ideas that this design effort has produced. The benefits of testing the key concepts with on-sun testing at performance levels that simulate the power tower plant conditions is enormous as real data gathered has demonstrated that the receiver innovations have provided the measurable gains the analysis has shown. This confirmation is the root of innovative efforts so that information is gained on whether or not the receiver concepts will work in practical operating conditions. This design and testing effort is very important to the long term growth and success of power tower technology. The information gained from this project will help sustain the innovative ideas that will further promote future CSP Power Towers. 